\title{
Functionalization of Enzymatically Treated Apple Pomace from Juice Production by Extrusion Processing
}

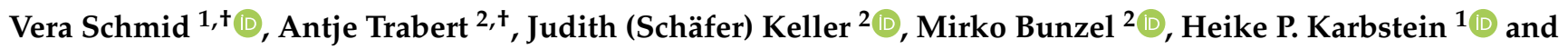 \\ M. Azad Emin 1,*
}

Citation: Schmid, V.; Trabert, A.; Keller, J.(.; Bunzel, M.; Karbstein, H.P.; Emin, M.A. Functionalization of Enzymatically Treated Apple Pomace from Juice Production by Extrusion Processing. Foods 2021, 10, 485. https://doi.org/10.3390/ foods10030485

Academic Editor: Danyang Ying

Received: 22 January 2021

Accepted: 18 February 2021

Published: 24 February 2021

Publisher's Note: MDPI stays neutral with regard to jurisdictional claims in published maps and institutional affiliations.

Copyright: (c) 2021 by the authors. Licensee MDPI, Basel, Switzerland. This article is an open access article distributed under the terms and conditions of the Creative Commons Attribution (CC BY) license (https:// creativecommons.org/licenses/by/ $4.0 /)$.
1 Institute of Process Engineering in Life Sciences, Chair of Food Process Engineering, Karlsruhe Institute of Technology (KIT), 76131 Karlsruhe, Germany; vera.schmid@kit.edu (V.S.); heike.karbstein@kit.edu (H.P.K.)

2 Institute of Applied Biosciences, Department of Food Chemistry and Phytochemistry, Karlsruhe Institute of Technology (KIT), 76131 Karlsruhe, Germany; antje.trabert@kit.edu (A.T.); judith.schaefer@kit.edu (J.K.); mirko.bunzel@kit.edu (M.B.)

* Correspondence: azad.emin@kit.edu; Tel.: +49-721-608-48311

+ Both authors contributed equally to this work.

\begin{abstract}
Food by-products can be used as natural and sustainable food ingredients. However, a modification is needed to improve the technofunctional properties according to the specific needs of designated applications. A lab-scale twin-screw extruder was used to process enzymatically treated apple pomace from commercial fruit juice production. To vary the range of the thermomechanical treatment, various screw speeds $\left(200,600,1000 \mathrm{~min}^{-1}\right)$, and screw configurations were applied to the raw material. Detailed chemical and functional analyses were performed to develop a comprehensive understanding of the impact of the extrusion processing on apple pomace composition and technofunctional properties as well as structures of individual polymers. Extrusion at moderate thermomechanical conditions increased the water absorption, swelling, and viscosity of the material. An increase in thermomechanical stress resulted in a higher water solubility index, but negatively affected the water absorption index, viscosity, and swelling. Scanning electron microscopy showed an extrusion-processing-related disruption of the cell wall. Dietary fiber analysis revealed an increase of soluble dietary fiber from 12.6 to $17.2 \mathrm{~g} / 100 \mathrm{~g}$ dry matter at maximum thermo-mechanical treatment. Dietary fiber polysaccharide analysis demonstrated compositional changes, mainly in the insoluble dietary fiber fraction. In short, pectin polysaccharides seem to be susceptible to thermo-mechanical stress, especially arabinans as neutral side chains of rhamnogalacturonan I.
\end{abstract}

Keywords: plant cell walls; by-products; dietary fiber; non-starch polysaccharides; upcycling; valorization; rheological properties; viscosity

\section{Introduction}

Clarified apple juice is one of the most-consumed juices in the world. Enzyme technology is often used to increase the juice yield and for juice clarification [1-3]. Apple pomace remains as major by-product of juice processing. As only a small portion is used for pectin extraction or as animal feed [4], tons of apple pomace are disposed of as waste [5]. To date, there is no efficient method for the conversion of apple pomace into high-value products; thus, apple pomace has very little to no economic value. At the same time, there is a growing demand of consumers for healthy and sustainable foods [6,7].

Apple pomace is a source of potentially healthy nutrients. Being rich in dietary fiber (Total Dietary Fiber (TDF): 60-90 g/100 g dm) and phytochemicals such as phloridzin, chlorogenic acid, and quercetin glycosides [4,5,8-10], it has the potential to be used as a valuable food ingredient. However, it shows poor technofunctional properties, e.g., low water solubility and adsorption, as well as low or no thickening and gelling properties, limiting its industrial applications in food products $[5,8,11,12]$. 
Previous studies showed that this limitation can be overcome by modifying the cell wall structure, leading to a significant improvement of the technofunctional properties [6]. Chemical, enzymatic, thermal, and/or mechanical treatment can modify the technofunctional properties. In this regard, extrusion processing is a promising technology. It is a continuous, highly versatile process, in which raw materials are heated and sheared simultaneously $[13,14]$.

Hwang et al. showed that extrusion processing of apple pomace resulted in an increase of soluble dietary fibers (SDF) from 8.2 to $18.2 \%$ and a decrease in insoluble dietary fiber (IDF) from 42.4 to $29.5 \%$, whereas its water holding capacity $\left(\sim 4 \mathrm{~mL} \cdot \mathrm{g}^{-1}\right)$ did not change at low thermomechanical treatment [15]. Liu et al. measured an increase in water solubility from 46 to $56.5 \mathrm{~g} \cdot 100 \mathrm{~g}^{-1}$ after the extrusion processing of apple pomace [16]. Also, an improvement in water-based pectin extraction after extrusion processing twice was observed [17]. The feasibility of using extrusion processing to modify apple pomace that has not been enzymatically treated during juice production was shown in our previous study. The results showed that the water solubility was increased from 5.2 to $33.0 \%$ and the water holding capacity of apple pomace from 7.3 to 21.4 . Also, the viscosity of apple pomace water dispersions was (positively) affected and was increased from 5 up to $396 \mathrm{~Pa} \cdot \mathrm{s}$ [18]. Dietary fiber and structural analyses confirmed the observations of Hwang et al. [15] that thermo-mechanical treatment results in a decrease in IDF along with an increase in SDF. Arabinose and galacturonic acid containing polysaccharides (pectins) of the IDF fraction were partially degraded [18].

In this study, enzymatically treated apple pomace, as it is the major by-product of apple juice production, was used. The enzymatically treated pomace differs from untreated apple pomace as the cell wall polymers are partially modified during the enzymatic treatment. This is expected to affect the modification of technofunctional properties by extrusion processing. Thus, the main focus of this study was to investigate the impact of extrusion processing on the chemical structure and technofunctional properties of the already enzymatically modified apple pomace. Therefore, the change in the structure and technofunctional properties of enzymatically treated apple pomace was analyzed as a function of thermomechanical treatment during extrusion processing, which was varied to a great extent by varying the screw configuration, screw speed, and water content.

\section{Materials and Methods}

\subsection{Materials, Chemicals, and Reagents}

Conventional apple pomace, which was enzymatically treated during juice processing, was received from J. Rettenmaier \& Söhne GmbH + Co KG (Rosenberg, Germany). The residual moisture content was $2.8 \pm 0.3 \%(w / w)$ (determined by Karl Fischer titration (Titroline alpha, Schott Instruments $\mathrm{GmbH}$, Mainz, Germany). According to the supplier, the dietary fiber content was 57.2 and the protein content $4.0 \mathrm{~g}$ per $100 \mathrm{~g} \mathrm{dm}$ (dry matter). Thermostable $\alpha$-amylase Termamyl $120 \mathrm{~L}$ (EC 3.2.1.1, from Bacillus licheniformis, $120 \mathrm{KNU} \cdot \mathrm{g}^{-1}$ ), amyloglucosidase AMG 300 L (EC 3.2.1.3, from Aspergillus niger, 300 AGU.g ${ }^{-1}$ ), and protease Alcalase 2.5 L (EC 3.4.21.62, from Bacillus licheniformis, $2.5 \mathrm{AU} \cdot \mathrm{g}^{-1}$ from Novozymes (Bagsværd, Denmark) were used to isolate dietary fiber on a preparative scale. Thermostable $\alpha$-amylase (EC 3.2.11, from Bacillus licheniformis, $3000 \mathrm{U} \cdot \mathrm{mL}^{-1}$ ), amyloglucosidase (EC 3.2.1.3 from Aspergillus niger), and protease (EC 3.4.21.14 from Bacillus licheniformis) (used for the analytical dietary fiber approach; the first two enzymes were also used to analyze starch contents), as well as endo-galactanase (EC 3.2.1.89 from Aspergillus niger) and endo-arabinanase (EC 3.2.1.99 from Aspergillus niger) were from Megazymes (Bray, Ireland).

\subsection{Extrusion Trials}

Extrusion trials were conducted using a co-rotating Thermo Scientific Process 11 hygenic twin-screw extruder (Thermo Fisher Scientific, Karlsruhe, Germany) with a lengthto-diameter (L/D) ratio of 40 . The barrel of the extruder consisted of eight sections, which could be heated and cooled separately. The barrel temperatures were adjusted to 
$\mathrm{T}_{\text {barrel1 }}=40{ }^{\circ} \mathrm{C}, \mathrm{T}_{\text {barrel2 }}=80^{\circ} \mathrm{C}, \mathrm{T}_{\text {barrel3 }}=100{ }^{\circ} \mathrm{C}$, and $\mathrm{T}_{\text {barrel5-8 }}=120^{\circ} \mathrm{C}$. The die adapter including the die $(2 \mathrm{~mm})$ was also heated to $120^{\circ} \mathrm{C}$. The apple pomace $\left(8 \mathrm{~kg} \cdot \mathrm{h}^{-1}\right)$ was fed into the first sections; water $\left(2 \mathrm{~kg} \cdot \mathrm{h}^{-1}\right)$ was added in the second section. Extrusion experiments were performed applying screw speeds of 200,600, and $1000 \mathrm{~min}^{-1}$. The screw configurations are shown in Figure 1. From configuration S1 to S4, the thermomechanical treatment on the material increases, by the implementation of two reverse elements (S2), four reverse elements (S3), and two reverse elements plus a kneading block (S4).

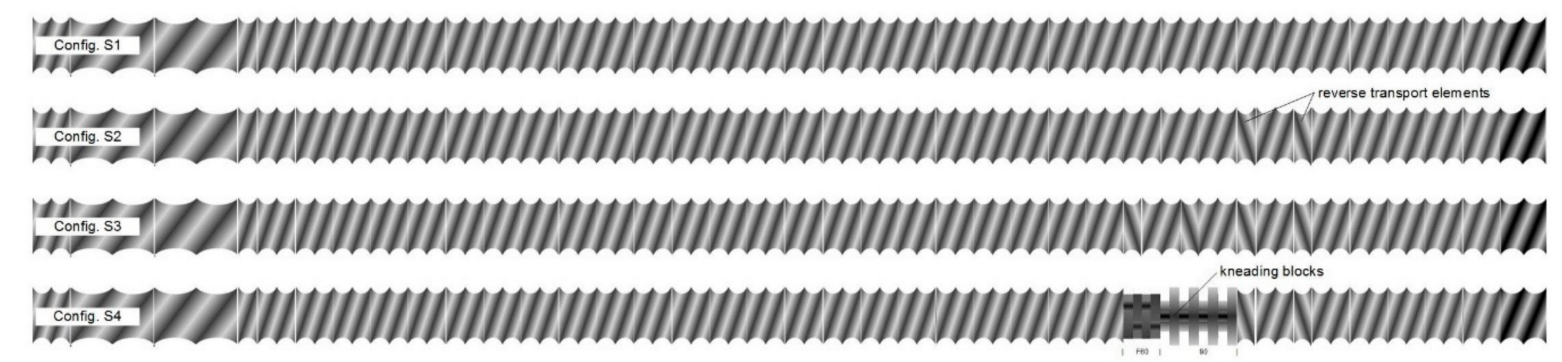

Figure 1. Schematic illustration of all screw configurations used. S1: only transport elements, S2 and S3: two and four reverse elements, S4: two reverse elements and a kneading block.

The melt temperature $T_{M}$ was measured in the die adapter. The specific mechanical energy input $(S M E)$ was calculated according to the following equation (1):

$$
\operatorname{SME}\left(\mathrm{Wh} \cdot \mathrm{kg}^{-1}\right)=\frac{\frac{n}{n_{\max }} \times \frac{M_{d}-M_{d, \text { unload }}}{100}}{\dot{m}} \times P_{\max }
$$

where $n$ and $n_{\max }$ are the actual and maximum screw speeds $\left(1000 \min ^{-1}\right) ; M_{d}$ and $M_{d, \text { unload }}$ are the actual and idle torques (\%); $\dot{m}$ represents the total mass flow $\left(1 \mathrm{~kg} \cdot \mathrm{h}^{-1}\right)$ and $P_{\max }$ the maximum engine power $(1.5 \mathrm{~kW})$. The residence time distribution (RTD) was measured by adding $0.1 \mathrm{~g}$ of $\mathrm{TiO}_{2}$ tracer to the barrel. By videography, 30 pictures per minute were taken and the color changes ( $L^{*}$ value) were analyzed using MATLAB. RTD trails were performed in triplicate.

The obtained extruded samples were vacuum packed and stored in the dark at room temperature.

\subsection{Compositional and Structural Analysis}

For all of the structural and technofunctional measurements, raw and extruded apple pomace was milled for $30 \mathrm{~s}$ (coffee mill M55, Petra Electric, Jettingen-Scheppach, Germany) and sieved $(140<\mathrm{x}<280 \mu \mathrm{m})$. The particle fraction was dried at $25^{\circ} \mathrm{C}$ and $8 \mathrm{mbar}$ in a vacuum dryer (Heraeus, Hanau, Germany) to constant weight.

All data are given as the mean \pm standard deviation $(n=3)$. All data related to isolated dietary fiber (molecular weight distribution, polysaccharide composition and interunit linkage, arabinan and galacatan profiling, degree of (pectin) esterification) are presented as the mean \pm range $/ 2(n=2)$. Statistical analyses were performed for all data, except for data related to isolated dietary fiber, by using the software OriginPro 2020 9.7.0.188. Differences among varietier were tested for statistical significance using ANOVA, followed by a Tukey test $(\alpha=0.005)$.

Free mono- and disaccharides. Free mono- and disaccharides were analyzed after aqueous extraction $(200 \mathrm{mg} / 10 \mathrm{~mL}$ water). The extraction process was accelerated by consecutive vortexing and sonication (temperature $<30{ }^{\circ} \mathrm{C}$ ), followed by centrifugation (10 min, $4500 \mathrm{rpm}$ ). This process was performed four times using fresh water after each centrifugation.

The resulting supernatants were combined, and an aliquot was filtered through a PTFE membrane filter $(45 \mu \mathrm{m})$. Ethanol (four times the volume of the aqueous aliquot) was added to precipitate residual polymeric material. The supernatant was evaporated, the 
residue was redissolved in water, and D-fucose $(200 \mu \mathrm{M})$ was added as an internal standard. Chromatographic analysis was performed using high-performance anion-exchange chromatography with pulsed amperometric detection (HPAEC-PAD) (Thermo Fisher Scientific, Waltham, MA, USA) as described previously [18,19].

Starch content. A suspension of the sample $(1 \mathrm{~g})$ in $0.08 \mathrm{M}$ phosphate buffer $(50 \mathrm{~mL}$, $\mathrm{pH}$ 6.0) was treated for $15 \mathrm{~min}$ at $60{ }^{\circ} \mathrm{C}$. Enzymatic digestion (thermostable $\alpha$-amylase (3000 U. $\left.\mathrm{mL}^{-1}, 92{ }^{\circ} \mathrm{C}, 15 \mathrm{~min}\right)$ and amyloglucosidase $\left(36,000 \mathrm{U} \cdot \mathrm{g}^{-1}, \mathrm{pH} 4.5,60{ }^{\circ} \mathrm{C}, 15 \mathrm{~min}\right)$ was applied to degrade the starch into glucose. Carrez clarification was performed $(1 \mathrm{~mL}$ of Carrez I solution $\left(150 \mathrm{~g} \cdot \mathrm{L}^{-1} \mathrm{~K}_{4}\left[\mathrm{Fe}(\mathrm{CN})_{6}\right] \cdot 3 \mathrm{H}_{2} \mathrm{O}\right)$ and $1 \mathrm{~mL}$ of Carrez II solution $\left(300 \mathrm{~g} \cdot \mathrm{L}^{-1}\right.$ $\left.\mathrm{ZnSO}_{4} \cdot 7 \mathrm{H}_{2} \mathrm{O}\right)$ ), and the $\mathrm{pH}$ was adjusted between 7.5 and 8.0. After centrifugation (5 min, $4500 \mathrm{rpm})$ and volume adjusting, the solution was diluted, and D-fucose $(200 \mu \mathrm{M})$ was added as an internal standard. The starch content was determined as the sum of anhydroglucose, quantified using HPAEC-PAD (Thermo Fisher Scientific, Waltham, MA, USA) as described previously [18,19].

Dietary fiber analysis. The IDF, SDF, and low-molecular-weight soluble dietary fiber (LMW-SDF) were determined by a combination of the methods of AOAC 985.29 [20] and AOAC 2009.01 [21] in order to exclude resistant starch but capture ethanol soluble fiber as also described in [18]. After enzymatic digestion with thermostable $\alpha$-amylase, amyloglucosidase, and protease, IDF and SDF were determined gravimetrically. Fiber contents were corrected for ash and residual protein (by Kjeldahl analysis) [22]. LMWSDF was analyzed from the filtrate of SDF. The filtrate was evaporated, desalted, and redissolved in water. The aqueous solution was analyzed for its LMW-SDF content by high performance liquid chromatography (HPLC) (Hitachi, Merck, Darmstadt, Germany) with refractive index (RI) detection (Knauer, Berlin, Germany) using two size exclusion columns (TSKgel G2500PWxl, $300 \mathrm{~mm} \times 7.8 \mathrm{~mm}$, particle size $7 \mu \mathrm{m}$, Tosoh, Tokyo, Japan) [18].

Dietary fiber isolation. The IDF and SDF were isolated on a preparative scale according to the principle of AOAC 985.29 (incubation with thermostable $\alpha$-amylase, amyloglucosidase, and protease) as detailed by Bunzel et al. [23].

Molecular weight distribution. SDF $\left(2 \mathrm{~g} \cdot \mathrm{L}^{-1}\right)$ was dissolved in $50 \mathrm{mM}$ sodium nitrate for $24 \mathrm{~h}$ at $40{ }^{\circ} \mathrm{C}$. The molecular weight distribution of SDF was analyzed by HPLC-RI (Hitachi, Merck, Darmstadt, Germany) using a guard column (TosohTSK-gel PWxl 40 mm $\times 6.0 \mathrm{~mm}$, particle size $12 \mu \mathrm{M}$ ) and two size exclusion columns in series (TosohTSK-gel G6000PWxl $300 \mathrm{~mm} \times 7.8 \mathrm{~mm}$, particle size $13 \mu \mathrm{M}$; TSK-gel G4000PWx1 $300 \mathrm{~mm} \times 7.8 \mathrm{~mm}$, particle size $10 \mu \mathrm{M}$ ) with $50 \mathrm{mM}$ sodium nitrate as eluent, a flow rate of $0.5 \mathrm{~mL} \cdot \mathrm{min}^{-1}$ and a temperature of $50{ }^{\circ} \mathrm{C}$ [18].

Polysaccharide composition. The monosaccharide composition of IDF was determined after sulfuric acid hydrolysis. SDF was depolymerized using methanolysis followed by TFA hydrolysis. Liberated monosaccharides were analyzed by HPAEC-PAD (Thermo Fisher Scientific, Waltham, MA, USA) [19]. To determine the composition of LMW-SDF, a preparative separation of mono- and disaccharides by HPLC (Hitachi, Merck, Darmstadt, Germany) with RI detection (Knauer, Berlin, Germany) was necessary as detailed in Schmid et al. [18]: The monosaccharide composition of extracted LWW-SDF was analyzed by HPAEC-PAD (Thermo Fisher Scientific, Waltham, MA, USA) after TFA hydrolysis [18].

Analysis of polysaccharide interunit linkages. To analyze the glyosidic linkages between the monosaccharides in the SDF and IDF polymers, methylation analysis was performed according to Gniechwitz et al. [24]. Fiber was swollen in dimethyl sulfoxide and treated twice with methyl iodide and $\mathrm{NaOH}$. Methylated polysaccharides were extracted into dichloromethane, hydrolyzed with TFA $\left(2 \mathrm{M}, 121^{\circ} \mathrm{C}\right)$ and reduced using sodium borodeuteride in aqueous ammonia. Acetylation was performed with acetic anhydride and 1-methylimidazole. Obtained partially methylated alditol acetates were determined semiquantitatively with gas chromatography-mass spectrometry (GC-MS) and GC with flame ionization detector (FID) using the molar response factors according to Sweet et al. [25].

Arabinan and galactan screening. Arabinan and galactan oligosaccharides were liberated from the neutral side chains of pectin by using endo-arabinanase and endo- 
galactanase and were determined semi-quantitatively using HPAEC-PAD (Thermo Fisher Scientific, Waltham, MA, USA) as described by Wefers and Bunzel [26].

Degree of (pectin) esterification. Methanol that was released from $15 \mathrm{mg}$ of sample material after a $2 \mathrm{~h}$ deesterification step with sonication $\left(2 \mathrm{M} \mathrm{NaOH}\right.$ in $\left.\mathrm{D}_{2} \mathrm{O}\right)$ was analyzed by ${ }^{1} \mathrm{H}$-NMR spectroscopy. 3-(Trimethylsilyl) propionic-2,2,3,3- $d_{4}$ acid sodium salt solution in $\mathrm{D}_{2} \mathrm{O}\left(0.2 \mathrm{mg} \cdot \mathrm{mL}^{-1}\right)$ was added as an internal standard. A standard Bruker ${ }^{1} \mathrm{H}-\mathrm{NMR}$ pulse program (zg30) was used: 65536 data points, acquisition time $3.28 \mathrm{~s}$, relaxation delay (D1) $35 \mathrm{~s}$ [18]. Polymer-bound galacturonic acid was analyzed photometrically according to the method of Blumenkrantz et al. [27].

\subsection{Scanning Electron Microscope}

The samples were fixed with platinum (Pt). A LEO 1530 (Carl Zeiss, Oberkochen, Germany) at high vacuum was used during scanning electron microscopy (SEM) to observe the particles. All images were taken at an operating voltage of $5 \mathrm{kV}$.

\subsection{Water Solubility Index (WSI) and Water Absorption Index (WAI)}

The WSI and WAI were determined in triplicate according to Anderson et al. [28] as described detailed in Schmid et al. [18]. In brief, milled, sieved, and dried apple pomace $(0.5 \mathrm{~g})$ was added to $19.5 \mathrm{~g}$ of demineralized water. Samples were mixed on a vortex mixer for $1 \mathrm{~min}$, followed by $24 \mathrm{~h}$ on an orbital shaker. For the WSI, samples were centrifuged at $4600 \times g$ for $50 \mathrm{~min}$ at $20^{\circ} \mathrm{C}$. No centrifugation step was performed for the WAI; instead, samples rested for $3 \mathrm{~h}$. For both WSI and WAI supernatants were removed, dried $\left(80^{\circ} \mathrm{C}\right.$, $72 \mathrm{~h}$ ), and weighed $(\mathrm{m})$, just as the precipitates. The WSI and WAI were calculated according to the following equations:

$$
\begin{gathered}
W S I=\frac{m_{\text {supernatant, dried }}}{m_{\text {powder }}} \\
W A I=\frac{m_{\text {precipitate, wet }}-m_{\text {precipitate, dried }}}{m_{\text {precipitate, dried }}}
\end{gathered}
$$

\subsection{Rheological Measurements}

Dispersions of raw or extruded apple pomace and water were made by mixing $1 \mathrm{~g}$ of ground, sieved, and dried sample with $10 \mathrm{~mL}$ of demineralized water. The dispersion was stirred on a magnetic mixer $\left(200 \mathrm{~min}^{-1}\right)$ for $10 \mathrm{~min}$, sealed with parafilm and rested for $50 \mathrm{~min}$. The rheological properties were determined by Anton Paar Rheometer MC 301 (Graz, Austria) using a parallel plate system $(50 \mathrm{~mm}$, smooth). The measurement gap was adjusted to $1.5 \mathrm{~mm}$. After a rest of $90 \mathrm{~s}$ in the geometry, samples underwent oscillatory shear at $25{ }^{\circ} \mathrm{C}$ with an amplitude of $0.1 \%$ and a frequency of $1 \mathrm{~Hz}$ (within the linear viscoelastic region to avoid a destruction of a network). The shown complex viscosity $\eta^{*}$ is a mean value of the last nine measurement points of each measurement. The measurements were performed in triplicate.

\subsection{Swelling by Using a Light Microscope}

The swelling of particles was determined by light microscopic (Eclipse LV100ND; Nikon, Tokyo, Japan) image processing. Demineralized water and sieved, dried pomace particles $(140<x<280 \mu \mathrm{m})$ were placed on the microscope slide and observed for $100 \mathrm{~min}$ at room temperature. The growth of particle size was evaluated by using ImageJ. Experiments were performed in duplicate.

\section{Results \& Discussion}

\subsection{Influence of Extrusion Parameters on the Extent of Thermomechanical Treatment}

To characterize the thermomechanical stresses applied to the raw material, the specific mechanical energy input (SME) and the material temperature $\left(\mathrm{T}_{\mathrm{M}}\right)$ were monitored. Figure 2 shows the influence of the screw speed on $\mathrm{SME}$ and $\mathrm{T}_{\mathrm{M}}$ for the screw configurations used. 

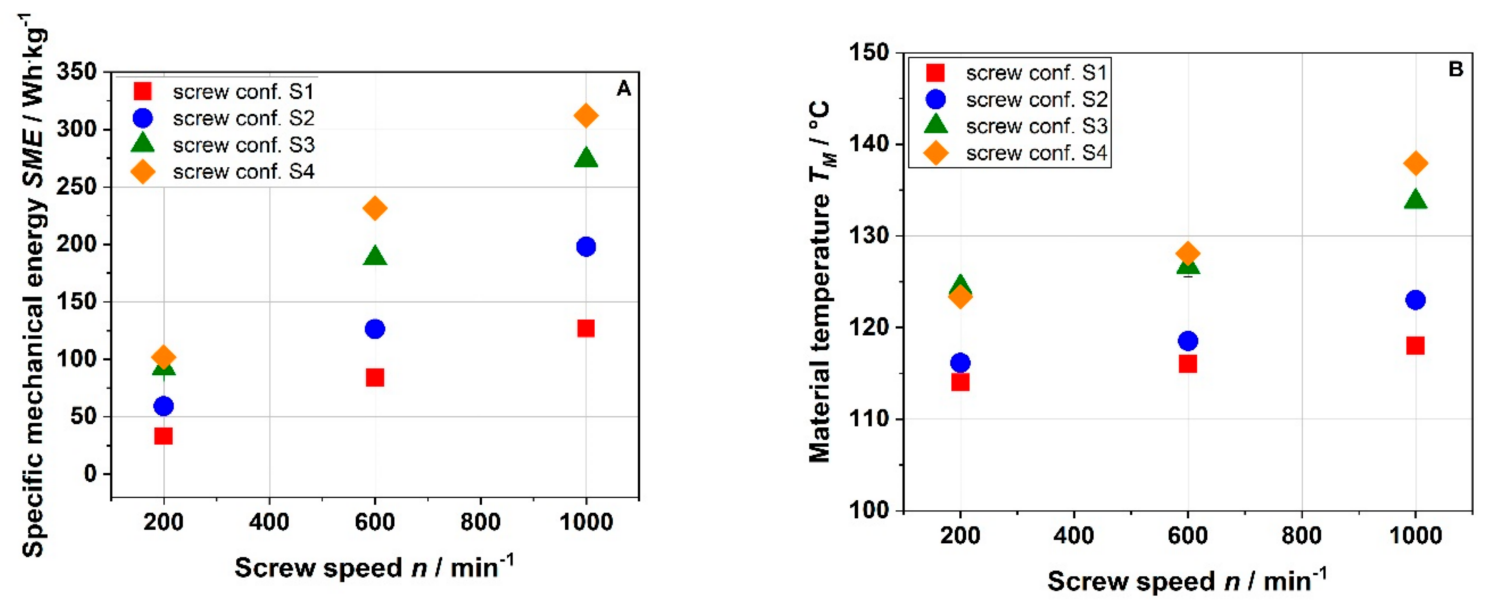

Figure 2. Specific mechanical energy input (SME) $(A)$ and material temperature $\left(\mathrm{T}_{\mathrm{M}}\right)(\mathbf{B})$ for conventional apple pomace treated at various screw speed and screw configurations (S1: only transport elements, S2: two reverse elements, S3: four reverse elements, S4: two reverse elements and a kneading block) at $22 \%$ water content and a barrel temperature $\mathrm{T}_{\mathrm{B}}$ of $120^{\circ} \mathrm{C}$.

In this study, the barrel temperature, water feed, and solid feed were kept constant; only the screw configuration and screw speed were varied. Increasing the screw speed from 200 to $1000 \mathrm{~min}^{-1}$ at a barrel temperature of $120{ }^{\circ} \mathrm{C}$ resulted in an increase in the SME for all screw configurations (Figure 2A). Screw configuration S1 showed the lowest SME, which increased by a factor of $\sim 3.8$ by increasing the screw speed from 200 to $1000 \mathrm{~min}^{-1}$. As expected, the SME increased with the number of reverse elements (S2 and S3). The highest SME values were observed for screw configuration S4, which included two reverse elements plus a kneading block. Reverse elements and kneading blocks restrict the flow of the raw material and intensify the mixing and shear, thus increasing the energy input (SME) [29].

SME and $\mathrm{T}_{\mathrm{M}}$ (Figure $2 \mathrm{~B}$ ) are linked with each other as viscous dissipation results in temperature increase. The lowest $\mathrm{T}_{\mathrm{M}}$ was observed for screw configuration $\mathrm{S} 1$, which consisted only of forward elements. The effect of the screw speed on the processing conditions was a function of the screw configuration used. Compared to a mild screw configuration (S1), the use of reverse elements as well as kneading blocks (S2-S4) led to a higher increase in the intensity of thermomechanical treatment with screw speed. This effect was more apparent for SME than $\mathrm{T}_{\mathrm{M}}$.

The residence time of the material in the extruder depends also on the screw configuration. At longer residence time, the material is exposed to the thermal stresses for a longer time. In addition to this, higher residence increases the probability that the material is exposed more often to the maximum thermal and mechanical stresses generated between the barrel wall and the tip of the screws [30]. Therefore, the chemical structures, and as a result, the technofunctional properties are potentially affected by the residence time. Figure 3 shows the residence time distribution (RTD) of all screw configurations used.

In general, the use of more restrictive elements is expected to result in longer residence time. Configurations S1 and S2, however, led to comparable RTDs within the range of 18 to $91 \mathrm{~s}$ and 17 to $65 \mathrm{~s}$, and mean residence times of 37 and $35 \mathrm{~s}$, respectively.

In comparison, $\mathrm{S3}$, with more screw elements, led to a significantly longer residence time with a range of 25 to $67 \mathrm{~s}$ and a mean residence time of $41 \mathrm{~s}$.

The longest residence time was observed for S4, with the range of 27 to $69 \mathrm{~s}$ and a mean residence time of $44 \mathrm{~s}$.

Overall, the results show that changing the screw speed and configuration led to a variation in thermomechanical treatment to a great extent with $S M E, T_{M}$, and mean residence time in the ranges of 33 to $312 \mathrm{Wh} \cdot \mathrm{kg}^{-1}, 114$ to $138^{\circ} \mathrm{C}$, and 33 to $45 \mathrm{~s}$, respectively. 


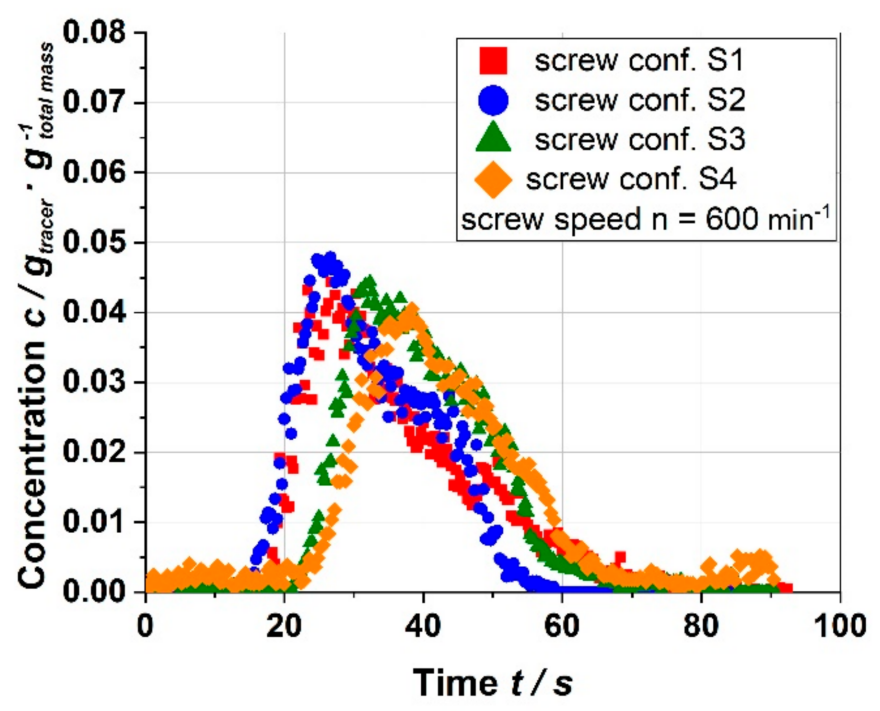

Figure 3. Residence time distribution for various screw configurations (screw speed: $600 \mathrm{~min}^{-1}$ and water content: $22 \%$, barrel temperature: $120{ }^{\circ} \mathrm{C}$; S1: only transport elements, S2: two reverse elements, S3: four reverse elements, S4: two reverse elements and a kneading block).

\subsection{Influence of Extrusion Conditions on the Structure and Composition of Conventional Apple} Pomace

The impact of extrusion conditions on the structural characteristics of enzymatically treated apple pomace was examined by using screw configurations S1, S2, and S4. For each configuration, a barrel temperature of $120{ }^{\circ} \mathrm{C}$, a screw speed of $600 \mathrm{~min}^{-1}$, and a water content of $22 \%$ were used. Because the focus of this study was on non-starch polysaccharides, results and additional methods for other apple pomace constituents (before and after extrusion) are deposited as Appendix (Method Appendix A; protein, ash: Table A1; free mono- and disaccharides: Table A2; starch: Table A3). Most importantly, contents of mono-/disaccharides and starch did not change after extrusion, independent of the screw configuration used.

\subsubsection{Dietary Fiber Composition}

The IDF and SDF contents of enzymatically treated apple pomace were affected by extrusion, as previously demonstrated $[15,18]$. The IDF slightly decreased, whereas the SDF increased with intensified thermo-mechanical treatment (Table 1). In contrast to apple pomace that has not been enzymatically treated during juice processing [18], the raw material used in this study already contained LMW-SDF. LMW-SDF generated from cell wall polysaccharides during juice extraction was potentially not fully extracted into the juice. However, correlations between LMW-SDF contents and thermomechanical treatment, residence time, or screw configuration were not observed.

Table 1. Dietary fiber contents ( $\mathrm{g} / 100 \mathrm{~g}$ dm; mean value \pm standard deviation, $n=3$ ) of enzymatically treated apple pomace (raw and extruded). IDF: insoluble dietary fiber, SDF: soluble dietary fiber, LMW-SDF: low-molecular weight soluble dietary fiber. S1: only transport elements, S2: two reverse elements, S4: two reverse elements and a kneading block.

\begin{tabular}{ccccc}
\hline & Raw Material & S1 & S2 & S4 \\
\hline Total content $^{\mathrm{a}}$ & $52.7 \pm 2.6^{\mathrm{A}, \mathrm{B}}$ & $56.4 \pm 2.4^{\mathrm{A}, \mathrm{C}}$ & $52.3 \pm 3.1^{\mathrm{B}}$ & $57.1 \pm 3.1^{\mathrm{C}}$ \\
IDF $^{\mathrm{a}}$ & $38.3 \pm 1.0^{\mathrm{A}, \mathrm{B}}$ & $40.4 \pm 0.7^{\mathrm{A}}$ & $37.6 \pm 1.3^{\mathrm{A}, \mathrm{B}}$ & $36.7^{\mathrm{B}} \pm 1.3^{\mathrm{B}}$ \\
SDF $^{\mathrm{a}}$ & $12.6 \pm 1.1^{\mathrm{B}}$ & $12.9 \pm 0.5^{\mathrm{B}}$ & $13.1 \pm 1.5^{\mathrm{B}}$ & $17.2 \pm 1.3^{\mathrm{A}}$ \\
LMW-SDF $^{\mathrm{a}}$ & $1.8 \pm 0.5^{\mathrm{A}}$ & $3.1 \pm 1.2^{\mathrm{A}}$ & $1.6 \pm 0.3^{\mathrm{A}}$ & $3.2 \pm 0.4^{\mathrm{A}}$ \\
\hline
\end{tabular}

${ }^{\mathrm{a}}$ Mean values within a row that are marked with different letters differ significantly $(p<0.05)$. 
Dietary fiber contents of apple pomace were studied in the past $[8,18,31]$ demonstrating that apple variety affects fiber contents. To the best of our knowledge, however, the fiber contents of enzymatically treated apple pomace have not yet been analyzed. Nevertheless, the values analyzed here are the range of published data for untreated apple pomace (IDF $33-67 \%$, SDF 3-14\%).

\subsubsection{Polysaccharide Characterization: Molecular Weight Distribution of Soluble Dietary} Fiber Polysaccharides

The SDF data indicated that the structure of dietary fiber polysaccharides was mostly influenced by screw configuration S4 (highest thermo-mechanical stress). This is in line with data describing the molecular weight distribution (Figure 4). Only a slight broadening of the distribution was observed for SDF from samples treated with screw configurations S1 and S2, whereas broadening was more distinct for SDF from the sample treated with configuration S4. Interestingly, the SDF obtained from the sample treated with screw configuration S4 showed an additional peak (elution volume of $13.6 \mathrm{~mL}$ (> $670 \mathrm{kDa})$ ). This might be due to the formation of high molecular melanoidins as end products of the Maillard reaction. Generally, these results are in line with our previous data for apple pomace that has not been treated during juice extraction [18].

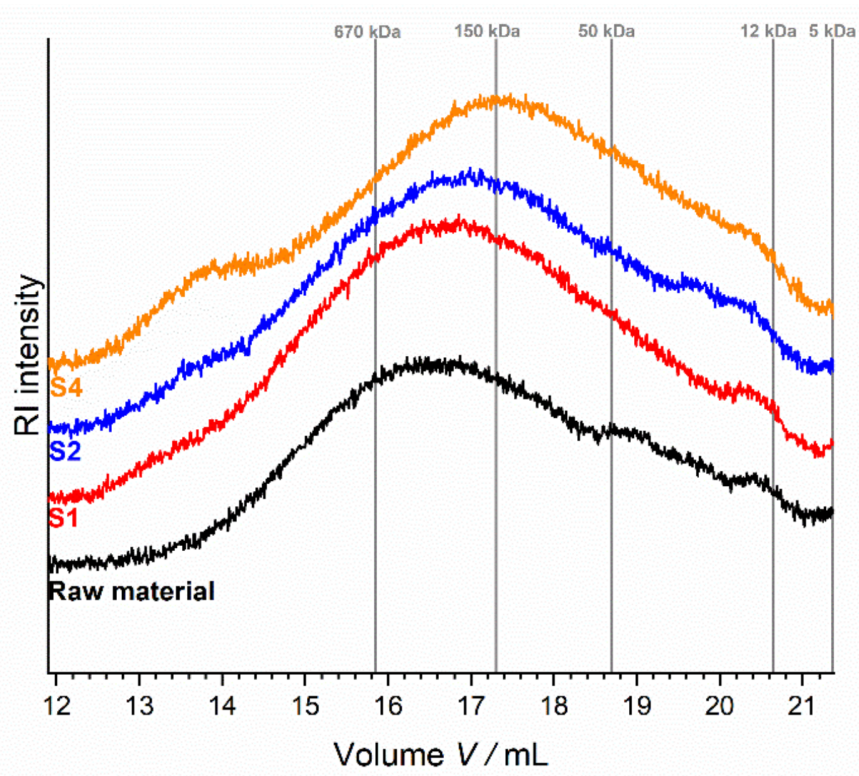

Figure 4. Molecular weight distribution of soluble dietary fiber (SDF) of enzymatically treated apple pomace (raw and extruded) as determined by using HPLC with refractive index (RI) detection. Dextrans of defined molecular weight were used for calibration (grey lines). S1: only transport elements, S2: two reverse elements, S4: two reverse elements and a kneading block.

3.2.3. Polysaccharide Characterization: Monomer Composition and Interunit Linkages of Fiber Polysaccharides

The monosaccharide composition of fiber polysaccharides was determined after sulfuric acid hydrolysis (IDF) (Table 2) or after methanolysis (SDF) (Table 5), respectively. Sulfuric acid hydrolysis tends to underestimate uronic acids including galacturonic acid, whereas crystalline cellulose is not hydrolyzed using methanolysis.

Cellulose, pectic polymers, and the hemicellulose xyloglucan have been previously described as dominant IDF polysaccharides from apples or apple pomace [18,32]. A comparable composition was found for enzymatically treated apple pomace: raw material IDF contained glucose $(49.6 \mathrm{~mol} \%$ ) as the main monosaccharide (vs. $43.3 \%$ in IDF from untreated apple pomace [18]). Besides cellulose, glucose can also be released from the hemicellulose xyloglucan. Xylose (10.4 mol\%) may stem from xyloglucans, but can also be released from xylans and xylogalacturonans. Arabinose (15.6 mol\%) and galactose 
(9.1 $\mathrm{mol} \%)$ are monomers of the neutral side chains of rhamnogalacturonan I. Galacturonic acid $(8.2 \mathrm{~mol} \%)$ and rhamnose $(1.8 \mathrm{~mol} \%)$ are pectic polysaccharide backbone constituents (homogalacturonan, rhamnogalacturonan I). Thus, up to $36 \mathrm{~mol} \%$ of the liberated monomers (including fucose) can be preliminarily assigned to pectic polymers, less than the IDF of untreated apple pomace (43 $\mathrm{mol} \%$ ) [18]. Because pectins are supposed to be a major target of the enzymes used, the shift in the overall monomer composition can easily be explained. However, other factors (apple variety, storage of apples etc.) may also affect the composition of the pomace after juice extraction.

Table 2. Monosaccharide composition ( $\mathrm{mol} \%$ ) of insoluble dietary fiber (IDF) of enzymatically treated apple pomace (raw and extruded) after sulfuric acid hydrolysis (mean value \pm range $/ 2, n=2$ ) Fuc: fucose, Rha: rhamnose, Ara: arabinose, Gal: galactose, Glc: glucose, Xyl: xylose, Man: mannose, GalA: galacturonic acid; GlcA: glucuronic acid, S1: only transport elements, S2: two reverse elements, S4: two reverse elements and a kneading block, bdl: below detection limit.

\begin{tabular}{ccccc}
\hline & Raw Material & S1 & S2 & S4 \\
\hline Fuc & $1.1 \pm 0.02$ & $1.2 \pm 0.04$ & $1.2 \pm 0.1$ & $1.3 \pm 0.01$ \\
Rha & $1.8 \pm 0.03$ & $1.7 \pm 0.003$ & $1.6 \pm 0.001$ & $1.4 \pm 0.02$ \\
Ara & $15.6 \pm 0.01$ & $13.1 \pm 0.1$ & $12.5 \pm 0.03$ & $9.2 \pm 0.04$ \\
Gal & $9.1 \pm 0.2$ & $8.2 \pm 0.01$ & $8.3 \pm 0.03$ & $8.0 \pm 0.1$ \\
Glc & $49.6 \pm 0.01$ & $51.1 \pm 0.1$ & $51.8 \pm 0.04$ & $56.4 \pm 0.1$ \\
Xyl & $10.4 \pm 0.1$ & $12.8 \pm 0.3$ & $13.2 \pm 0.2$ & $14.1 \pm 0.2$ \\
Man & $4.2 \pm 0.1$ & $4.1 \pm 0.1$ & $4.4 \pm 0.01$ & $4.6 \pm 0.01$ \\
GalA & $8.2 \pm 0.1$ & $7.7 \pm 0.1$ & $6.9 \pm 0.2$ & $5.0 \pm 0.1$ \\
GlcA & bdl & bdl & bdl & bdl \\
\hline
\end{tabular}

Assignment of the liberated monosaccharides to individual polysaccharides can be (partially) performed by using methylation analysis data (analysis of interunit linkages). Results of the neutral pectic side-chain profiling approach provided additional information about the structure of IDF polysaccharides. Data of the glycosidic linkage analysis of IDF are given in Table 3. Glucose was mainly 1,4-linked, suggesting, as expected, large amounts of cellulose. Besides cellulose, the xyloglucan backbone contains 1,4-linked glucopyranose units, too. Because 1,4,6-linked glucopyranose and terminal xylopyranose units were also identified, minor portions of 1,4-linked glucopyranose can be attributed to xyloglucans. 1,2-linked xylopyranose is a known structural element of xyloglucans. Only small amounts of 1,4-linked xylopyranose (3.8 $\mathrm{mol} \%)$ and 1,4-linked mannopyranose (3.8 $\mathrm{mol} \%$ ) units were detected in enzymatically treated apple pomace IDF, suggesting that xylans and linear mannans are quantitatively less important. The partially methylated alditol acetates of arabinose suggest arabinans (1,5-linked arabinofuranose as linear backbone units) with branches in positions $\mathrm{O}-3$ (primarily) and/or O-2. Glycosidic linkages of galactose units indicate a primarily linear structure.

Structures of the neutral pectic side chains were verified using a profiling approach published by Wefers and Bunzel [26] (Table 4). In addition to backbone oligosaccharides with branches in position O-3 (e.g., A-4a; Figure A1, Appendix B), O-2 (e.g., A-4b) or in both positions (e.g., A-5a) structural units that demonstrate dimeric side-chains (e.g., A-5b) were identified. Thus, the profiling approach verified methylation analysis data with regard to the predominance of branching in position $\mathrm{O}-3$ over branching in position $\mathrm{O}-2$ and branching in both positions. G-2a was the predominantly observed galactan oligosaccharide, a disaccharide representing 1,4-linked galactopyranose units of the galactan backbone (Table A4, Appendix B). Furthermore, structures that contain arabinopyranose units were identified: G-2c demonstrating internal 1,4-arabinopyranose and low amounts of G-2b demonstrating terminal arabinopyranose units. The presence of these galactan structural elements in apples was previously demonstrated by Wefers and Bunzel [32].

Monosaccharide composition data of IDF obtained from extruded samples revealed that increased thermo-mechanical stress results in decreased arabinose portions (down to 
$9.2 \mathrm{~mol} \%$ ) being consistent with data on extruded apple pomace that has not been enzyme treated [18]. This decrease is also reflected by methylation analysis data. Although there is no dramatic degradation of a single structural unit, it appears that extrusion-based changes affect slightly more branching positions, going along with decreased terminal arabinofuranose units. The decrease of 1,3,5- and 1,2,5-linked arabinofuranose units seems to be independent of the strength of the thermo-mechanical treatment. Only the reduction of terminal arabinofuranose units was more distinct when screw configuration S4 was used. Data of the arabinan profiling do not exactly match the methylation analysis data. Here, the portion of the $\mathrm{O}-3$ branched oligosaccharide A-4a did not decrease; however, the portion of the more strongly branched oligosaccharide A-5b, which also contains the 1,3,5-linked arabinofuranose unit, decreased. The same applies to the oligosaccharides with backbone linkages in position $\mathrm{O}-2$ (A-4b and A-5c, respectively), indicating that these slightly more complex side-chains are susceptible to extrusion-based degradation. More generally, the susceptibility of arabinans to thermomechanical stress has already been demonstrated for non-enzymatically treated apple pomace [18] and chokeberry pomace [33].

Table 3. Glyosidic linkage of insoluble dietary fiber (IDF) of enzymatically treated apple pomace (raw and extruded) $(\mathrm{mol} \%$, mean value \pm range $/ 2, n=2)$. t: terminal, p: pyranose, f: furanose, Rha: rhamnose, Ara: arabinose, Gal: galactose, Glc: glucose, Man: mannose, Xyl: xylose, S1: only transport elements, S2: two reverse elements, S4: two reverse elements and a kneading block.

\begin{tabular}{|c|c|c|c|c|}
\hline & Raw Material & S1 & $\mathrm{S} 2$ & S4 \\
\hline 1,2-Rhap & $0.8 \pm 0.1$ & $1.0 \pm 0.3$ & $0.9 \pm 0.01$ & $0.9 \pm 0.4$ \\
\hline 1,2,4-Rhap & $0.4 \pm 0.1$ & $0.5 \pm 0.1$ & $0.9 \pm 0.3$ & $0.4 \pm 0.1$ \\
\hline$\sum$ Rha & $1.2 \pm 0.1$ & $1.5 \pm 0.4$ & $1.8 \pm 0.3$ & $1.2 \pm 0.5$ \\
\hline t-Araf & $8.6 \pm 0.05$ & $8.5 \pm 1.4$ & $7.1 \pm 0.2$ & $6.0 \pm 0.03$ \\
\hline $\mathrm{t}$-Arap & $0.6 \pm 0.01$ & $0.5 \pm 0.05$ & $0.6 \pm 0.04$ & $0.6 \pm 0.04$ \\
\hline 1,2-Araf & $0.5 \pm 0.01$ & $0.3 \pm 0.02$ & $0.5 \pm 0.1$ & $0.3 \pm 0.04$ \\
\hline 1,3-Araf & $1.8 \pm 0.05$ & $1.5 \pm 0.3$ & $1.2 \pm 0.05$ & $1.4 \pm 0.3$ \\
\hline 1,5 -Araf $/ 1,4$-Arap & $11.5 \pm 0.03$ & $8.5 \pm 1.2$ & $7.1 \pm 0.5$ & $9.4 \pm 2.4$ \\
\hline 1,2,5-Araf & $1.7 \pm 0.04$ & $0.7 \pm 0.2$ & $0.6 \pm 0.1$ & $0.7 \pm 0.02$ \\
\hline 1,3,5-Araf & $5.3 \pm 0.02$ & $3.0 \pm 1.7$ & $3.3 \pm 0.4$ & $3.3 \pm 0.1$ \\
\hline 1,2,3,5-Araf & $7.5 \pm 0.1$ & $2.3 \pm 0.3$ & $2.6 \pm 0.5$ & $2.3 \pm 0.02$ \\
\hline$\sum$ Ara & $37.4 \pm 0.3$ & $25.4 \pm 5.1$ & $23.1 \pm 1.9$ & $23.9 \pm 3.0$ \\
\hline $\mathrm{t}-\mathrm{Gal} p$ & $3.7 \pm 0.01$ & $3.2 \pm 0.04$ & $2.5 \pm 0.1$ & $3.3 \pm 1.0$ \\
\hline 1,4-Galp & $4.0 \pm 0.03$ & $3.6 \pm 0.2$ & $3.6 \pm 0.1$ & $3.7 \pm 0.8$ \\
\hline 1,6-Galp & $0.6 \pm 0.02$ & $0.5 \pm 0.03$ & $0.5 \pm 0.04$ & $0.7 \pm 0.2$ \\
\hline $1,4,6-\mathrm{Gal} p$ & $0.3 \pm 0.004$ & $0.3 \pm 0.1$ & $0.2 \pm 0.02$ & $0.3 \pm 0.1$ \\
\hline$\sum \mathrm{Gal}$ & $8.6 \pm 0.1$ & $7.5 \pm 0.3$ & $6.7 \pm 0.3$ & $8.0 \pm 2.0$ \\
\hline $\mathrm{t}-\mathrm{Glc} p$ & $0.9 \pm 0.1$ & $0.9 \pm 0.1$ & $0.8 \pm 0.01$ & $0.9 \pm 0.4$ \\
\hline 1,4-Glcp & $24.9 \pm 0.2$ & $36.6 \pm 4.2$ & $41.3 \pm 2.6$ & $32.8 \pm 3.1$ \\
\hline $1,4,6-G l c p$ & $4.7 \pm 0.04$ & $7.8 \pm 0.8$ & $8.1 \pm 0.7$ & $7.0 \pm 2.2$ \\
\hline$\sum$ Glc & $30.5 \pm 0.4$ & $45.3 \pm 5.0$ & $50.1 \pm 3.3$ & $40.7 \pm 5.7$ \\
\hline t-Man $p$ & $0.3 \pm 0.1$ & $0.3 \pm 0.1$ & $0.2 \pm 0.0005$ & $0.2 \pm 0.1$ \\
\hline 1,4-Man $p$ & $3.8 \pm 0.04$ & $3.2 \pm 0.2$ & $2.8 \pm 0.5$ & $4.2 \pm 1.6$ \\
\hline 1,4,6-Man $p$ & $0.6 \pm 0.02$ & $0.5 \pm 0.05$ & $0.5 \pm 0.1$ & $0.7 \pm 0.2$ \\
\hline$\sum$ Man & $4.7 \pm 0.2$ & $4.0 \pm 0.4$ & $3.4 \pm 0.6$ & $5.2 \pm 1.9$ \\
\hline $\mathrm{t}-\mathrm{Xyl} p$ & $9.4 \pm 0.05$ & $8.9 \pm 0.1$ & $8.1 \pm 2.8$ & $10.3 \pm 0.9$ \\
\hline $1,2-X_{y l} p^{a}$ & $4.4 \pm 0.02$ & $3.5 \pm 0.2$ & $2.8 \pm 0.2$ & $4.6 \pm 0.4$ \\
\hline $1,4-X y l p^{a}$ & $3.8 \pm 0.01$ & $4.0 \pm 0.7$ & $3.9 \pm 0.3$ & $6.1 \pm 0.9$ \\
\hline$\sum \mathrm{Xyl}$ & $17.6 \pm 0.1$ & $16.4 \pm 1.1$ & $14.8 \pm 1.2$ & $20.9 \pm 2.2$ \\
\hline
\end{tabular}

$\bar{a}$ Coeluting, determined from the area ratio of the characteristic fragment ion peaks. 1,2-Xylp: $\mathrm{m} / \mathrm{z} 117,1,4-X y l p$ : $m / z 118$.

Besides arabinose, the portion of galacturonic acid appears to decrease with increasing thermo-mechanical stress (monosaccharide composition). This is accompanied by an increase in the portions of xylose and glucose. Overall, it can be recognized that treatments using screw configurations S1 and S2 result in comparable IDF polysaccharide modifications (based on monomer composition). As shown in Figure 2, configurations S1 and $S 2$ result in similar $T_{M}$, whereas configuration $S 4$ generates a markedly higher $T_{M}$. 
Furthermore, configuration S4 results in a much longer residence time as compared to configurations S1 and S2.

Table 4. Composition (mol\%) of liberated arabinan oligosaccharides after incubation of insoluble dietary fiber (IDF) of enzymatically treated apple pomace (raw and extruded) with endo-arabinanase (mean value \pm range $/ 2, n=2$ ). S1: only transport elements, S2: two reverse elements, S4: two reverse elements and a kneading block, bdl: below detection limit, nd: not detected.

\begin{tabular}{ccccc}
\hline Compound & Raw Material & S1 & S2 & S4 \\
\hline A-2a & $84.1 \pm 0.4$ & $86.5 \pm 0.7$ & $84.6 \pm 0.4$ & $87.1 \pm 1.8$ \\
A-4a & $6.8 \pm 0.1$ & $5.8 \pm 0.04$ & $7.4 \pm 0.1$ & $7.1 \pm 1.1$ \\
A-4b & $1.6 \pm 0.003$ & $1.0 \pm 0.1$ & $1.7 \pm 0.04$ & $1.8 \pm 0.3$ \\
A-5a & bdl & $0.7 \pm 0.04$ & $0.6 \pm 0.1$ & $0.8 \pm 0.2$ \\
A-5b & $4.2 \pm 0.3$ & $3.3 \pm 0.4$ & $2.8 \pm 0.2$ & $1.8 \pm 0.2$ \\
A-5c & $2.3 \pm 0.002$ & $1.5 \pm 0.1$ & $1.4 \pm 0.1$ & bdl \\
A-6a & $1.0 \pm 0.1$ & $0.9 \pm 0.03$ & $1.2 \pm 0.1$ & $1.4 \pm 0.3$ \\
A-7a & nd & $0.1 \pm 0.03$ & $0.1 \pm 0.004$ & nd \\
A-7b & bdl & $0.1 \pm 0.02$ & $0.2 \pm 0.001$ & nd \\
\hline
\end{tabular}

SDF polysaccharides consisted mostly of pectic polymers (about $88 \mathrm{~mol} \%$, Table 5). Just as in IDF, the dominant neutral side chains were arabinans as indicated by a higher portion of arabinose $(39.9 \mathrm{~mol} \%)$ as compared to galactose $(10.3 \mathrm{~mol} \%)$. Methylation analysis data (Table A5, Appendix B) confirmed that SDF polysaccharides mostly consist of arabinan rich pectins. Again, arabinan branching in position O-3 dominates over branching in position $O-2$, as also demonstrated by the results of the arabinan profiling approach (Table A6, Appendix B). Dimeric side-chains attached in position $\mathrm{O}-3$ of the backbone (reflected by the oligosaccharide A-5b liberated in the arabinan profiling approach) were also found in appreciable portions in SDF arabinans. Xyloglucan-specific linkage types such as 1,4,6-linked glucopyranose units in combination with 1,2-linked xylopyranose units (Table A5, Appendix B) demonstrate the existence of xyloglucans in this fiber fraction, although in minor amounts only.

Table 5. Monosaccharide composition ( $\mathrm{mol} \%$ ) of soluble dietary fiber (SDF) of enzymatically treated apple pomace (raw and extruded) after methanolysis (mean value \pm range/2, $n=2$ ) Fuc: fucose, Rha: rhamnose, Ara: arabinose, Gal: galactose, Glc: glucose, Xyl: xylose, Man: mannose, GalA: galacturonic acid, GlcA: glucuronic acid, S1: only transport elements, S2: two reverse elements, S4: two reverse elements and a kneading block, bdl: below detection limit.

\begin{tabular}{ccccc}
\hline & Raw Material & S1 & S2 & S4 \\
\hline Fuc & bdl & bdl & bdl & bdl \\
Rha & $4.4 \pm 0.1$ & $5.4 \pm 0.2$ & $5.1 \pm 0.2$ & $5.6 \pm 0.2$ \\
Ara & $39.9 \pm 0.04$ & $36.3 \pm 0.5$ & $38.1 \pm 0.01$ & $41.2 \pm 0.3$ \\
Gal & $10.3 \pm 0.2$ & $12.1 \pm 0.3$ & $12.1 \pm 0.2$ & $13.7 \pm 0.1$ \\
Glc & $3.4 \pm 0.2$ & $4.4 \pm 0.9$ & $4.8 \pm 0.4$ & $3.4 \pm 0.2$ \\
Xyl & $3.4 \pm 0.1$ & $4.4 \pm 0.4$ & $4.7 \pm 0.3$ & $5.1 \pm 0.2$ \\
Man & $5.8 \pm 0.01$ & $5.4 \pm 0.1$ & $5.1 \pm 0.04$ & $4.4 \pm 0.1$ \\
GalA & $32.8 \pm 0.2$ & $32.0 \pm 0.1$ & $30.1 \pm 0.4$ & $26.7 \pm 0.5$ \\
GlcA & bdl & bdl & bdl & bdl \\
\hline
\end{tabular}

Analysis of the extruded samples revealed that the galacturonic acid content in the SDF polysaccharides decreased. All other changes were rather minor; the amount of arabinose in the SDF polysaccharides does not appear to be largely affected by thermo-mechanical treatment. Methylation analysis failed to demonstrate major changes in the interunit linkages of the SDF polysaccharides before and after extrusion (Table A5, Appendix B). The only more pronounced and consistent difference is an increase in terminal arabinofuranose units. The arabinan (Table A6, Appendix B) and galactan profiling approaches (Table A4, 
Appendix B) did not show any further evidence of specific extrusion based structural changes of SDF polysaccharides.

The LWD-SDF fractions of the raw material and the extruded samples mainly contain arabinose, glucose, and galacturonic acid. Although the arabinose portions appear to increase and the glucose portions appear to decrease with thermo-mechanical treatment, an unambiguous statement is difficult (Table A7, Appendix B).

\subsubsection{Polysaccharide Characterization: Pectin Esterification}

It is known that the degree of pectin esterification has an influence on the gel-forming properties of pectin. Therefore, the degree of polymer-bound galacturonic acid esterification was studied in the raw material and after extrusion. Yet, extrusion seems to have no distinct impact on the degree of esterification of enzymatically treated apple pomace. The IDF pectins of the raw material showed a degree of esterification of $18 \%$. With the maximum thermomechanical treatment (screw configuration S4), the percentage was $15 \%$. Only minor changes were also observed for the SDF pectins, where the portion increased from $23 \%$ (raw material) to $26 \%$ (screw configuration S4). Given the fact that these numbers are based on two separate analyses (analysis of polymer-bound galacturonic acid and analysis of methanol after esterification) the analyzed esterification degrees do not indicate extrusion based modifications of this parameter.

\subsubsection{Influence of Process Conditions on Surface of Extrudate Particles}

Besides chemical structure, the macroscopic structure is also altered by extrusion processing. Figure 5 depicts scanning electron microscope (SEM) images of raw and extruded apple pomace.

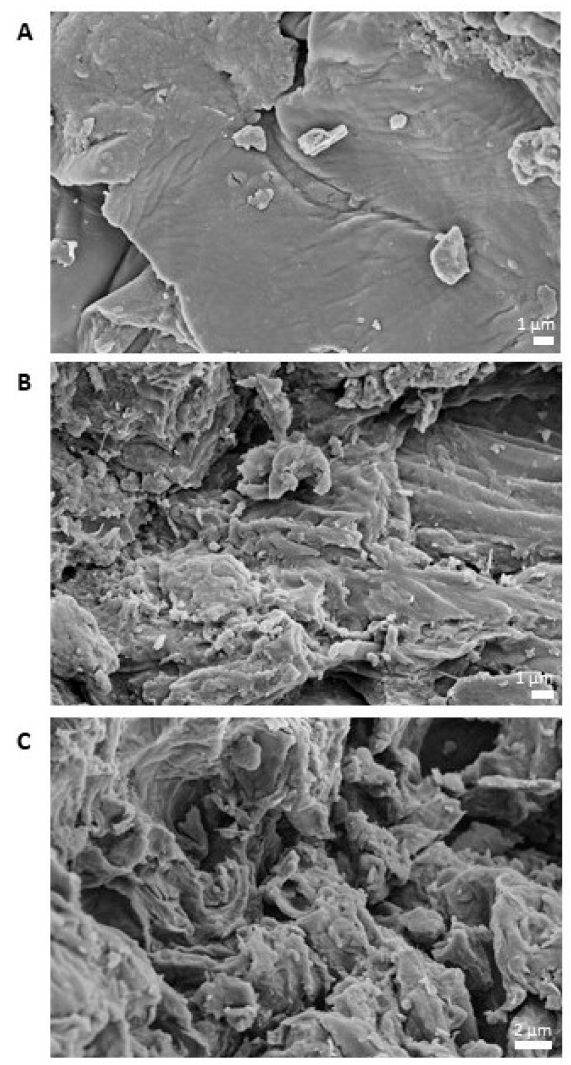

Figure 5. Scanning electron microscope images of conventional apple pomace surfaces. (A) Raw material. (B) Extruded, screw speed: $200 \mathrm{~min}^{-1}$, screw configuration S1, barrel temperature: $120{ }^{\circ} \mathrm{C}$, water content: $22 \%$. (C) Extruded, screw speed: $200 \mathrm{~min}^{-1}$, screw configuration S4, barrel temperature: $120{ }^{\circ} \mathrm{C}$, water content: $22 \%$. 
Figure 5A shows the smooth, closed surface of the raw apple pomace, which was enzymatically treated during juice processing. Figure $5 \mathrm{~B}-\mathrm{C}$ show samples that were extruded using screw configuration S1 or S4, respectively. The images show that an application thermomechanical treatment results in a rougher surface, which becomes more prominent at higher treatment intensity (Figure 5C).

\subsection{Influence of Extrusion Conditions on the Functional Properties of Apple Pomace}

\subsubsection{Water Solubility Index and Water Absorption Index}

The water solubility indices (WSI) of raw and extruded apple pomace are shown in Figure 6. The WSI of raw material was $31.5 \%$. By extrusion processing, the WSI can be increased by $14 \%$. At milder process conditions (S1), however, the WSI was lower than the WSI of the raw material. An increase in the thermomechanical treatment by an increase in screw speed and change in screw configuration $(\mathrm{S} 1<\mathrm{S} 2<\mathrm{S} 3<\mathrm{S} 4)$ led to higher WSI values. The correlation between the SME and WSI was also observed by Hwang et al. [15], however, only for one screw configuration. Application of the most intensive thermomechanical treatment (S4) resulted in the highest WSI, as well as the highest amount of SDF (Table 1), which is probably due to an intensive degradation of cell wall polymers. These results show that, in addition to the SME and $\mathrm{T}_{\mathrm{M}}$, the screw configuration had a significant effect, which could be related to the change in the residence time (Figure 3) leading to longer and more frequent exposure of the material to the local maximum stresses along the extruder screws [34].
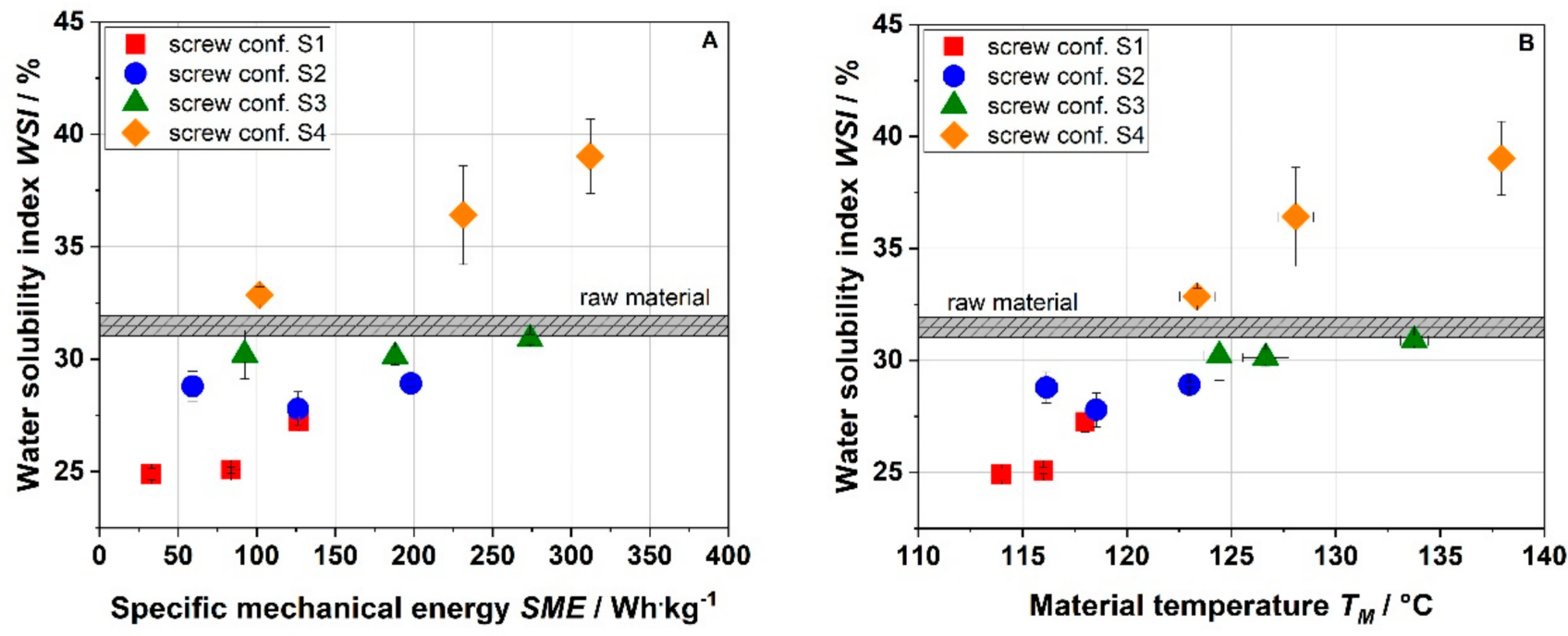

Figure 6. Effect of specific mechanical energy SME (A) and material temperature $\mathrm{T}_{\mathrm{M}}(\mathbf{B})$ on water solubility index (WSI) of apple pomace for various screw configurations at a water content of $22 \%$. S1: only transport elements, S2: two reverse elements, S3: four reverse elements, S4: two reverse elements and a kneading block.

Figure 7 shows the water absorption indices (WAI) of raw and extruded apple pomace. The WAI of the raw material was 8.8. Depending on the process conditions, the WAI was increased up to 23.3. For milder process conditions (S1) and moderate process conditions (S2, S3), the WAI decreased with the SME and $\mathrm{T}_{\mathrm{M}}$. In contrast, at intensive process conditions (S4), the WAI increased with the SME and $\mathrm{T}_{\mathrm{M}}$. Scanning electron microscope images of the surface of the raw and extruded apple pomace particles showed that by extrusion processing the surface was broken up (Figure 5). It can be assumed that by this alteration more water can infiltrate and be absorbed. Intensification of thermomechanical stress may disrupt the macromolecular structure to an extent that water absorption decreases. 

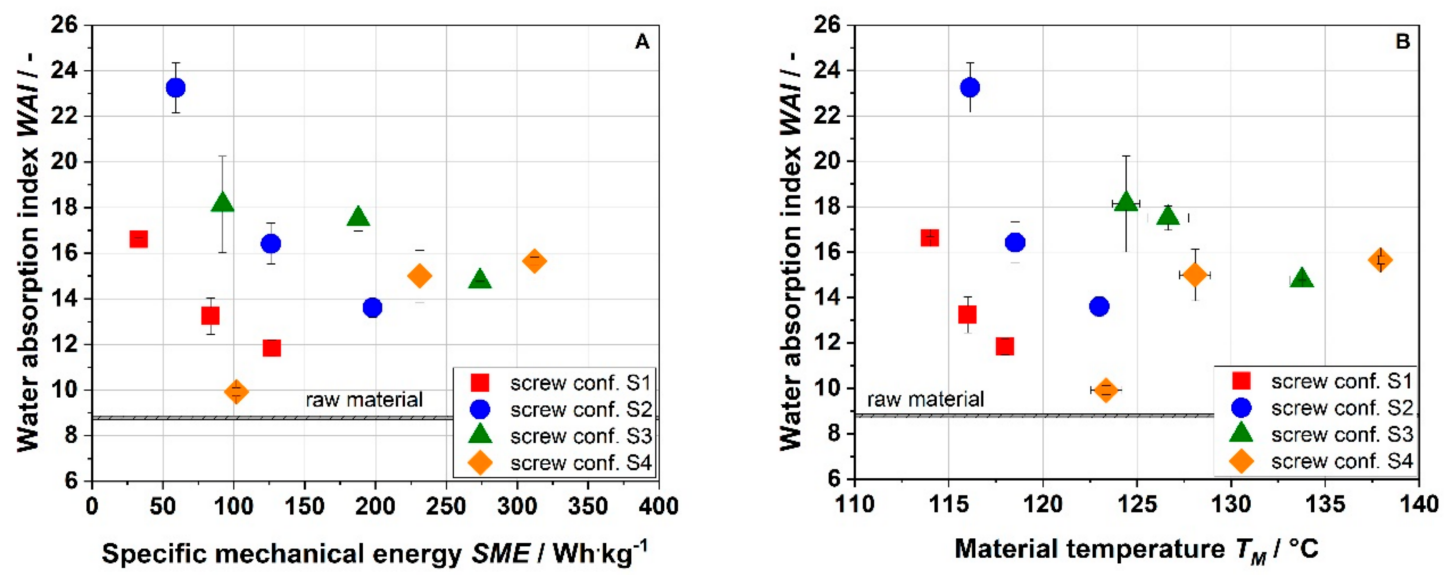

Figure 7. Effect of specific mechanical energy SME (A) and material temperature $\mathrm{T}_{\mathrm{M}}(\mathbf{B})$ on water absorption index (WAI) of apple pomace for various screw configurations at a water content of $22 \%$. S1: only transport elements, S2: two reverse elements, S3: four reverse elements, S4: two reverse elements and a kneading block.

\subsubsection{Swelling}

Figure 8 shows the change in the size of raw and extruded apple pomace particles swelling in water. Samples, which were characterized structurally in detail, were chosen for the swelling investigations.

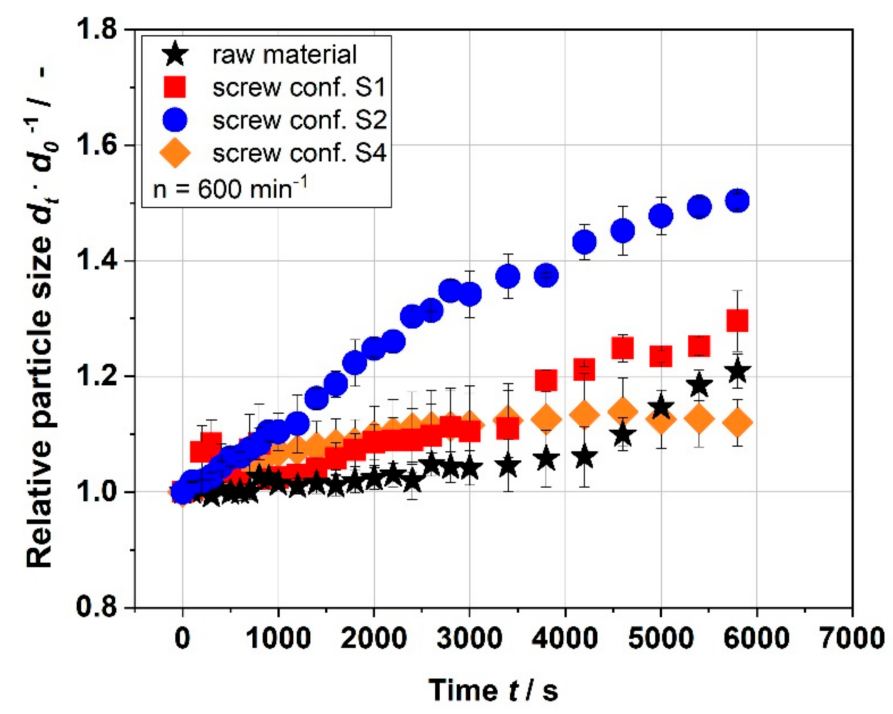

Figure 8. Change of size of raw material and various extruded samples by microscopic image analysis for a time period of almost $1 \mathrm{~h} 40 \mathrm{~min}$. The relative particle size is the ratio between the area occupied by a particle at time $t\left(A_{t}\right)$ and the area occupied by the particle at the initial time $\left(\mathrm{A}_{0}\right)$. S1: only transport elements, S2: two reverse elements, S4: two reverse elements and a kneading block).

The results in Figure 8 show that the size of the raw material particles did not change for almost $4500 \mathrm{~s}$. Afterwards, the particles of the raw material started to grow. In comparison, the extruded samples resulted in an increase in particle size right from the beginning. For moderate process conditions (S2), swelling of the apple pomace particles was most pronounced. The milder (S1) and most intense thermomechanical treatment (S4) had a smaller impact on particle size growth. Comparing the results with the WAI data (Figure 7), it can be concluded that the samples that swell to a larger extend also absorb more water, as expected. Figure 9 shows that the particles extruded at the most intense conditions (S4) are the smallest and least compact, which is in accordance with the surface structure depicted by SEM images in Figure 5 . 


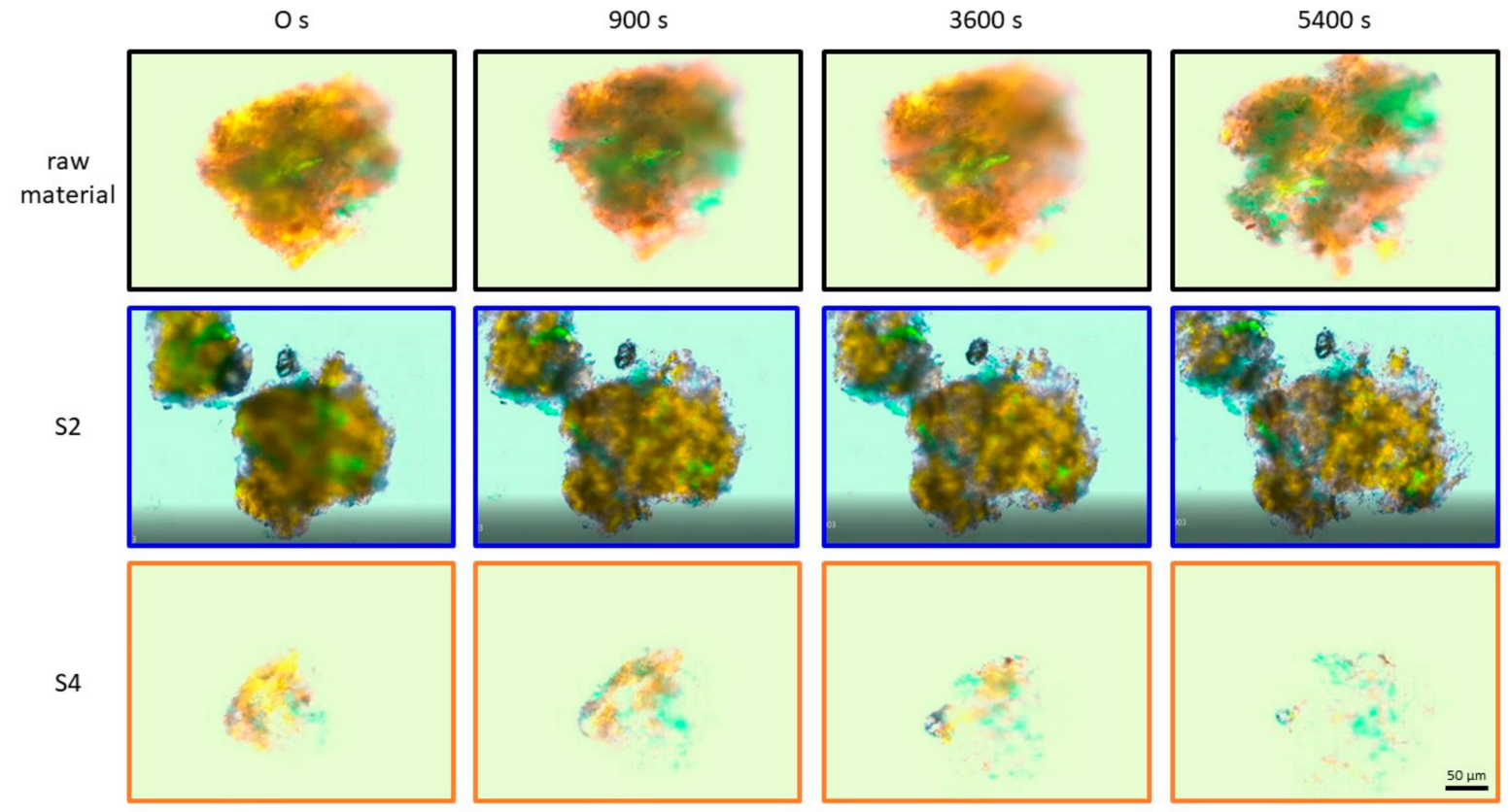

Figure 9. Microscope pictures of raw material, screw configuration S2 and S4 at $600 \mathrm{~min}^{-1}$ at 0, 900, 3600, 5400 s. S2: two reverse elements, S4: two reverse elements and a kneading block).

These results might suggest that the extrusion processing leads to more porous cell wall materials that could absorb more water than raw material, whereas excessive treatment could lead to fragmentation and decrease in this porous structure necessary for the water absorption and swelling. From a structural point of view (Tables 1-5), samples that were extruded using screw configurations S1 and S2 were comparable, whereas the sample that was extruded applying configuration S4 showed more distinct differences in structure, which is in accordance with these findings. Nevertheless, more investigations are necessary to draw a strong conclusion.

\subsubsection{Viscosity}

For the application of apple pomace as a thickener and stabilizer in food matrices, it is essential to know the rheological behavior. The complex viscosities of apple pomace-water dispersions are depicted in Figure 10.
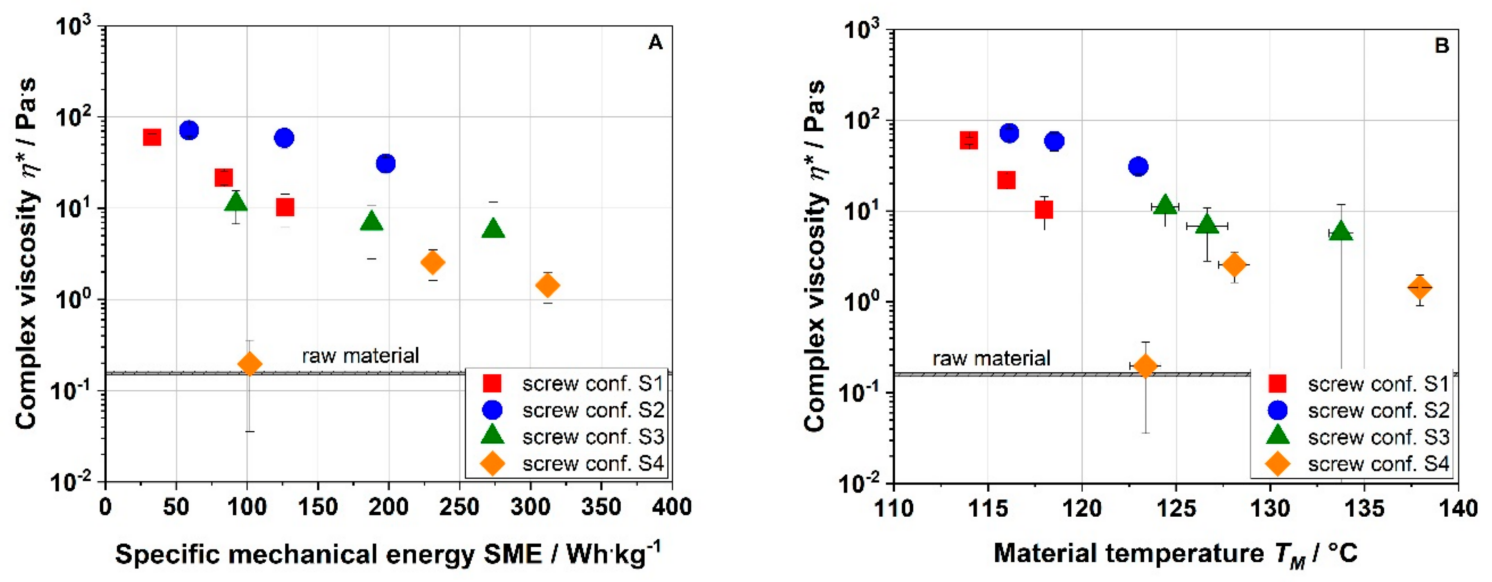

Figure 10. Effect of specific mechanical energy SME (A) and material temperature $T_{M}(\mathbf{B})$ on complex viscosity $\left(\eta^{*}\right)$ of apple pomace for various screw configurations at water content of $22 \%$. S1: only transport elements, S2: two reverse elements, S3: four reverse elements, S4: two reverse elements and a kneading block. 
The complex viscosity of the raw material was $0.16 \mathrm{~Pa} \cdot \mathrm{s}$. Both low and moderate thermomechanical treatment (S1 and S2) resulted in an immense increase in complex viscosity up to max. $71.4 \mathrm{~Pa} \cdot \mathrm{s}\left(\mathrm{S} 2,200 \mathrm{~min}^{-1}\right)$. With increasing SME and $\mathrm{T}_{\mathrm{M}}$, the complex viscosity decreased for screw configurations S1-S3. In contrast, for the screw configuration S4, which represents the highest thermomechanical treatment, the values of complex viscosity increased from 0.15 to 2.55 to $1.43 \mathrm{~Pa} \cdot \mathrm{s}$ with increasing SME and $\mathrm{T}_{\mathrm{M}}$. These results are similar to the WAI results (Figure 7), suggesting that the water absorption and swelling (Figures 8 and 9) due to macromolecular cell wall alterations play an important role in the thickening behavior of the extruded samples. Thus it is all about swelling not the gelling of individual components as assumed [11,35,36].

\section{Conclusions}

This study investigates the functionalization of enzymatically treated apple pomace from commercial fruit juice production by extrusion processing. The results showed that the total DF content changed only slightly by varying the intensity of thermomechanical treatment, whereas the amount of SDF increased. The results may indicate a specific degradation reaction into the pectin polysaccharides. In detail, a decrease of arabinose and galacturonic acid in the IDF and a decrease of galacturonic acid in the SDF could be determined. The extrusion of the samples led to the modification of water solubility, water absorption, and viscosity.

Depending on the conditions, the WSI could be varied in the range of 24.9 to $39.0 \%$, whereas the WAI was highest for moderate thermomechanical treatment (23.3) and lowest for intensive thermomechanical treatment (9.9), which is slightly higher than raw material (8.8). The viscosity of apple pomace-water dispersion was increased from 0.2 up to 71.4 Pa.s. The analysis of the macrostructure suggests that the extrusion leads to a more porous structure of apple pomace particles, which is important for the swelling of the particles and thus for water absorption and viscosity, respectively.

The functional properties showed no apparent correlation with SME and TM. For more mechanistic analysis, the analysis of the local extrusion conditions and the application of defined treatments should be considered in further studies. Nevertheless, the modification of enzymatically treated apple pomace makes it suitable as a potential natural thickener in dessert and dairy products or as a filler in bread and sausage products.

Author Contributions: Conceptualization, M.B. and M.A.E.; methodology, V.S., A.T., J.K.; investigation, V.S., A.T.; resources, M.B., H.P.K., M.A.E.; data curation, V.S., A.T.; writing-original draft preparation, V.S., A.T.; writing—review and editing, V.S., J.K., M.B., H.P.K., M.A.E.; visualization, V.S., A.T.; supervision, J.K., M.B., M.A.E.; project administration, V.S., J.K., M.B., M.A.E.; funding acquisition, M.B., H.P.K., M.A.E. All authors have read and agreed to the published version of the manuscript.

Funding: The IGF research project $(20518 \mathrm{~N})$ of the FEI was supported via AiF within the program for promoting the Industrial Collective Research (IGF) of the German Ministry of Economics and Energy (BMWi), bases on a resolution of German Parliament.

Institutional Review Board Statement: Not applicable.

Informed Consent Statement: Not applicable.

Data Availability Statement: Not applicable.

Acknowledgments: The authors would like to express their thanks to Kerstin Sauther, Andrea Butterbrodt, Felix Ellwanger, Samira Heinrich, and Bettina Bastius for supporting the sample preparation and analyses, ThermoFisher Scientific for providing the extruder Process11 including all the needed equipment, as well as J. Rettenmaier\&Söhne GmbH + Co KG for supplying the apple pomace.

Conflicts of Interest: The authors declare no conflict of interest. 


\section{Appendix A}

Protein content. The protein content was analyzed via liberated ammonia after Kjeldahl digestion of $100 \mathrm{mg}$ of sample [21]. An ammonia electrode was used for ammonia detection.

Ash content. The ash content was determined gravimetrically after incineration $\left(500^{\circ} \mathrm{C}, 4 \mathrm{~h}\right)$.

\section{Appendix B}

Table A1. Protein and ash contents ( $\mathrm{g} / 100 \mathrm{~g} \mathrm{dm}$, mean value \pm standard deviation, $n=3$ ) of extruded enzymatically treated apple pomace (raw and extruded). S1: only transport elements, S2: two reverse elements, S4: two reverse elements and a kneading block.

\begin{tabular}{ccccc}
\hline & Raw Material & S1 & S2 & S4 \\
\hline Protein content $^{\mathrm{a}}$ & $2.6 \pm 0.4^{\mathrm{A}}$ & $2.3 \pm 0.1^{\mathrm{A}}$ & $2.8 \pm 0.1^{\mathrm{A}}$ & $2.5 \pm 0.3^{\mathrm{A}}$ \\
Ash content $^{\mathrm{a}}$ & $1.6 \pm 0.03^{\mathrm{A}}$ & $1.5 \pm 0.02^{\mathrm{A}}$ & $1.6 \pm 0.06^{\mathrm{A}}$ & $1.6 \pm 0.1^{\mathrm{A}}$ \\
\hline
\end{tabular}

${ }^{a}$ Mean values within a row that are marked with different letters differ significantly $(p<0.05)$.

Table A2. Contents of free mono- and disaccharides $(\mathrm{g} / 100 \mathrm{~g} \mathrm{dm}$, mean value \pm standard deviation, $n=3$ ) of enzymatically treated apple pomace (raw and extruded). S1: only transport elements, S2: two reverse elements, S4: two reverse elements and a kneading block.

\begin{tabular}{ccccc}
\hline & Raw Material & S1 & S2 & S4 \\
\hline Glucose $^{\mathrm{a}}$ & $6.2 \pm 0.9^{\mathrm{A}}$ & $6.2 \pm 1.3^{\mathrm{A}}$ & $5.8 \pm 0.2^{\mathrm{A}}$ & $7.1 \pm 1.9^{\mathrm{A}}$ \\
Fructose $^{\mathrm{a}}$ & $12.7 \pm 1.1^{\mathrm{A}}$ & $11.7 \pm 0.9^{\mathrm{A}}$ & $11.8 \pm 0.4^{\mathrm{A}}$ & $12.6 \pm 0.7^{\mathrm{A}}$ \\
Sucrose $^{\mathrm{a}}$ & $4.1 \pm 2.0^{\mathrm{A}}$ & $3.4 \pm 1.5^{\mathrm{A}}$ & $4.0 \pm 0.3^{\mathrm{A}}$ & $3.4 \pm 0.7^{\mathrm{A}}$ \\
Maltose $^{\mathrm{a}}$ & $0.4 \pm 0.1^{\mathrm{A}}$ & $0.5 \pm 0.1^{\mathrm{A}}$ & $0.5 \pm 0.1^{\mathrm{A}}$ & $0.5 \pm 0.1^{\mathrm{A}}$ \\
\hline
\end{tabular}

${ }^{a}$ Mean values within a row that are marked with different letters differ significantly $(p<0.05)$.

Table A3. Starch contents ( $\mathrm{g} / 100 \mathrm{~g} \mathrm{dm}$, mean value \pm standard deviation, $n=3$ ) of enzymatically treated apple pomace (raw and extruded). S1: only transport elements, S2: two reverse elements, S4: two reverse elements and a kneading block.

\begin{tabular}{ccccc}
\hline & Raw Material & S1 & S2 & S4 \\
\hline Starch content $^{\mathrm{a}}$ & $8.3 \pm 0.4^{\mathrm{A}}$ & $7.8 \pm 0.6^{\mathrm{A}}$ & $7.7 \pm 0.3^{\mathrm{A}}$ & $8.0 \pm 0.3^{\mathrm{A}}$ \\
\hline
\end{tabular}

${ }^{a}$ Mean values within a row that are marked with different letters differ significantly $(p<0.05)$.

Table A4. Composition (mol\%) of galactan oligosaccharides after incubation of insoluble dietary fiber (IDF) and soluble dietary fiber (SDF) of enzymatically treated apple pomace (raw and extruded) with endo-galactanase (mean value \pm range $/ 2, n=2$ ). S1: only transport elements, S2: two reverse elements, S4: two reverse elements and a kneading block, bdl: below detection limit, nd: not detected.

\begin{tabular}{ccccccccc}
\hline \multicolumn{2}{c}{ Compound } & \multicolumn{2}{c}{ Raw Material } & \multicolumn{2}{c}{ S1 } & \multicolumn{2}{c}{ S2 } & \multicolumn{2}{c}{ S4 } \\
\hline & IDF & SDF & IDF & SDF & IDF & SDF & IDF & SDF \\
G-2a & $95.3 \pm 0.7$ & 100.0 & $93.3 \pm 0.4$ & 100.0 & $94.3 \pm 0.2$ & 100.0 & $93.7 \pm 0.7$ & 100.0 \\
G-2b & bdl & bdl & $4.2 \pm 0.4$ & bdl & $3.7 \pm 0.1$ & bdl & $2.5 \pm 0.3$ & bdl \\
G-2c & $4.7 \pm 0.7$ & nd & $2.4 \pm 0.04$ & nd & $1.9 \pm 0.2$ & nd & $2.5 \pm 0.5$ & nd \\
\hline
\end{tabular}


Table A5. Glyosidic linkages of soluble dietary fiber (SDF) polysaccharides of enzymatically treated apple pomace (raw and extruded) (mol\%, mean value \pm range $/ 2, n=2)$. $\mathrm{t}$ : terminal, p: pyranose, $\mathrm{f}$ : furanose, Rha: rhamnose, Ara: arabinose, Gal: galactose, Glc: glucose, Man: mannose, Xyl: xylose, S1: only transport elements, S2: two reverse elements, S4: two reverse elements and a kneading block, nd: not detected.

\begin{tabular}{|c|c|c|c|c|}
\hline & Raw Material & S1 & S2 & S4 \\
\hline 1,2-Rhap & $1.1 \pm 0.02$ & $1.4 \pm 0.2$ & $0.9 \pm 0.04$ & $2.1 \pm 0.2$ \\
\hline 1,2,4-Rhap & $0.4 \pm 0.1$ & $0.4 \pm 0.1$ & $0.4 \pm 0.01$ & $1.3 \pm 0.5$ \\
\hline$\sum$ Rha & $1.6 \pm 0.1$ & $1.8 \pm 0.3$ & $1.3 \pm 0.1$ & $3.4 \pm 0.6$ \\
\hline t-Araf & $17.5 \pm 0.9$ & $24.8 \pm 1.2$ & $23.6 \pm 0.2$ & $22.6 \pm 0.6$ \\
\hline t-Arap & $0.9 \pm 0.2$ & $1.0 \pm 0.2$ & $1.1 \pm 0.2$ & $0.7 \pm 0.1$ \\
\hline 1,2-Araf & $0.7 \pm 0.05$ & $0.5 \pm 0.01$ & $0.5 \pm 0.02$ & $0.5 \pm 0.001$ \\
\hline 1,3-Araf & $3.4 \pm 0.1$ & $3.8 \pm 0.9$ & $3.0 \pm 0.01$ & $3.4 \pm 0.1$ \\
\hline 1,5 -Araf $/ 1,4$-Arap & $23.0 \pm 0.5$ & $22.2 \pm 0.2$ & $24.5 \pm 0.4$ & $22.6 \pm 0.04$ \\
\hline 1,2,5-Araf & $2.8 \pm 0.3$ & $1.4 \pm 0.7$ & $1.3 \pm 0.8$ & $2.4 \pm 0.04$ \\
\hline 1,3,5-Araf & $9.6 \pm 0.6$ & $8.1 \pm 0.2$ & $8.7 \pm 0.1$ & $9.0 \pm 0.5$ \\
\hline 1,2,3,5-Araf & $10.9 \pm 1.9$ & $8.8 \pm 0.7$ & $9.1 \pm 2.1$ & $7.0 \pm 0.03$ \\
\hline$\sum$ Ara & $68.7 \pm 4.6$ & $70.8 \pm 4.1$ & $71.9 \pm 3.8$ & $67.9 \pm 1.5$ \\
\hline $\mathrm{t}-\mathrm{Gal} p$ & $2.6 \pm 0.4$ & $3.3 \pm 0.4$ & $2.0 \pm 0.2$ & $3.3 \pm 0.2$ \\
\hline 1,4-Galp & $6.6 \pm 0.4$ & $3.7 \pm 0.1$ & $3.7 \pm 0.3$ & $4.6 \pm 0.1$ \\
\hline $1,4,6-\mathrm{Gal} p$ & $2.0 \pm 0.4$ & $2.3 \pm 0.2$ & $2.0 \pm 0.2$ & $1.9 \pm 0.1$ \\
\hline$\sum \mathrm{Gal}$ & $11.2 \pm 1.2$ & $9.3 \pm 0.6$ & $7.7 \pm 0.7$ & $9.8 \pm 0.4$ \\
\hline $\mathrm{t}-\mathrm{Gl} c p$ & $1.0 \pm 0.01$ & $1.9 \pm 0.8$ & $0.5 \pm 0.03$ & $0.9 \pm 0.1$ \\
\hline $1,4-G l c p$ & $7.0 \pm 1.7$ & $4.3 \pm 2.3$ & $5.8 \pm 0.7$ & $4.9 \pm 0.3$ \\
\hline $1,4,6-$ Glcp & $1.4 \pm 0.01$ & $2.3 \pm 1.0$ & $2.6 \pm 0.2$ & $2.7 \pm 0.2$ \\
\hline$\sum \mathrm{Glc}$ & $9.4 \pm 1.7$ & $8.6 \pm 4.1$ & $8.9 \pm 1.0$ & $8.5 \pm 0.6$ \\
\hline t-Man $p$ & $1.4 \pm 0.2$ & nd & $0.7 \pm 0.1$ & $1.0 \pm 0.3$ \\
\hline 1,4-Man $p$ & $1.3 \pm 0.2$ & $0.8 \pm 0.1$ & $1.5 \pm 0.4$ & $1.2 \pm 0.1$ \\
\hline$\sum$ Man & $2.7 \pm 0.4$ & $0.8 \pm 0.1$ & $2.2 \pm 0.5$ & $2.2 \pm 0.4$ \\
\hline $\mathrm{t}-\mathrm{Xyl} p$ & $4.0 \pm 0.5$ & $6.3 \pm 0.4$ & $5.5 \pm 0.2$ & $5.8 \pm 0.5$ \\
\hline $1,2-\mathrm{Xyl} p^{\mathrm{a}}$ & $1.9 \pm 0.2$ & $1.5 \pm 0.05$ & $1.5 \pm 0.1$ & $1.5 \pm 0.01$ \\
\hline $1,4-X y l p^{a}$ & $0.5 \pm 0.5$ & $1.0 \pm 0.1$ & $1.0 \pm 0.01$ & $0.9 \pm 0.05$ \\
\hline$\sum \mathrm{Xyl}$ & $6.4 \pm 1.3$ & $8.8 \pm 0.5$ & $8.0 \pm 0.3$ & $8.1 \pm 0.6$ \\
\hline
\end{tabular}

a Coeluting, determined from the area ratio of the characteristic fragment ion peaks. 1,2-Xylp: $\mathrm{m} / \mathrm{z} 117,1,4-X y l p$ : $\mathrm{m} / \mathrm{z} 118$.

Table A6. Composition (mol\%) of arabinan oligosaccharides after incubation of soluble dietary fiber (SDF) of enzymatically treated apple pomace (raw and extruded) with endo-arabinanase (mean value \pm range $/ 2, n=2$ ). S1: only transport elements, S2: two reverse elements, S4: two reverse elements and a kneading block, bdl: below decetion limit, nd: not detected.

\begin{tabular}{ccccc}
\hline Compound & Raw Material & S1 & S2 & S4 \\
\hline A-2a & $81.1 \pm 2.6$ & $85.0 \pm 2.8$ & $82.6 \pm 2.4$ & $80.5 \pm 0.3$ \\
A-4a & $10.4 \pm 0.3$ & $9.1 \pm 0.5$ & $9.7 \pm 1.1$ & $10.9 \pm 0.1$ \\
A-4b & $2.4 \pm 0.6$ & $1.5 \pm 0.7$ & $1.4 \pm 0.5$ & $1.8 \pm 0.1$ \\
A-5a & bdl & $1.1 \pm 1.0$ & $1.7 \pm 0.8$ & $2.1 \pm 0.5$ \\
A-5b & $4.0 \pm 0.4$ & $3.3 \pm 0.7$ & $4.5 \pm 0.02$ & $4.7 \pm 0.2$ \\
A-5c & bdl & bdl & bdl & bdl \\
A-6a & bdl & bdl & nd & nd \\
A-7a & nd & nd & nd & nd \\
A-7b & $2.0 \pm 1.3$ & nd & nd & nd \\
\hline
\end{tabular}


Table A7. Monosaccharide composition (mol\%) of low-molecular weight soluble dietary fiber (LMW$\mathrm{SDF}$ ) of enzymatically treated apple pomace (raw and extruded) after TFA hydrolysis (mean value \pm standard deviation, $n=3$ ) Rha: rhamnose, Ara: arabinose, Gal: galactose, Glc: glucose, Xyl: xylose, Man: mannose, GalA: galacturonic acid, S1: only transport elements, S2: two reverse elements, S4: two reverse elements and a kneading block, bdl: below detection limit.

\begin{tabular}{ccccc}
\hline & Raw Material & S1 & S2 & S4 \\
\hline Rha & bdl & bdl & bdl & bdl \\
Ara $^{\text {a }}$ & $56.6 \pm 8.8^{\mathrm{A}}$ & $59.7 \pm 18.7^{\mathrm{A}}$ & $66.9 \pm 10.5^{\mathrm{A}}$ & $72.2 \pm 11.6^{\mathrm{A}}$ \\
Gal $^{\mathrm{a}}$ & $4.4 \pm 0.9^{\mathrm{A}}$ & bdl & bdl & $3.8^{\mathrm{A}} \pm 1.6^{\mathrm{A}}$ \\
Glc $^{\mathrm{a}}$ & $21.9 \pm 4.3^{\mathrm{A}}$ & $15.1 \pm 5.0^{\mathrm{A}, \mathrm{B}}$ & $12.3 \pm 3.4^{\mathrm{A}, \mathrm{B}}$ & $10.0 \pm 2.5^{\mathrm{B}}$ \\
Xyl & bdl & bdl & bdl & bdl \\
Man $^{\text {a }}$ & $3.7 \pm 1.6^{\mathrm{A}}$ & $6.8 \pm 4.2^{\mathrm{A}}$ & $9.3 \pm 5.1^{\mathrm{A}}$ & $3.0 \pm 0.6^{\mathrm{A}}$ \\
GalA $^{\mathrm{a}}$ & $13.4 \pm 6.4^{\mathrm{A}}$ & $18.4 \pm 10.8^{\mathrm{A}}$ & $11.6 \pm 9.3^{\mathrm{A}}$ & $11.0 \pm 7.5^{\mathrm{A}}$ \\
\hline
\end{tabular}

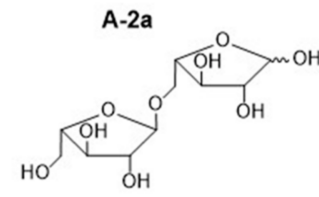<smiles>[R]O[C@@H]1N[C@@H]2O[C@@H](O)[C@@H](O)[C@H]2O1</smiles><smiles>COC1OC2OC(O)C1O2</smiles>

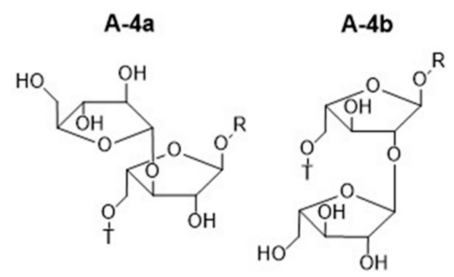

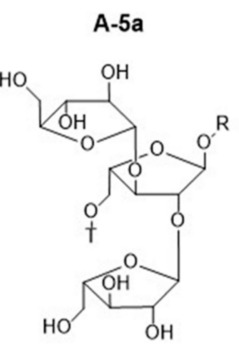

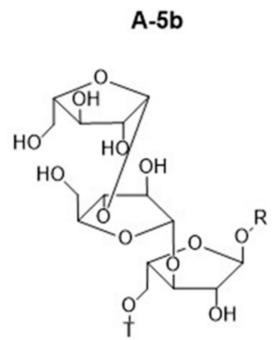

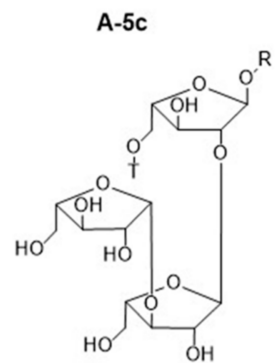

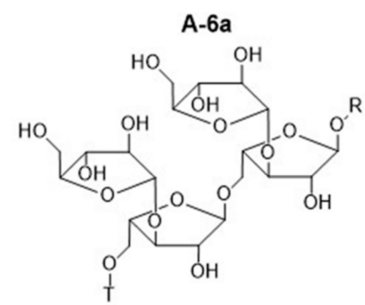

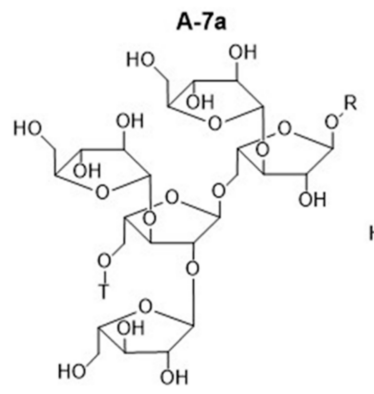

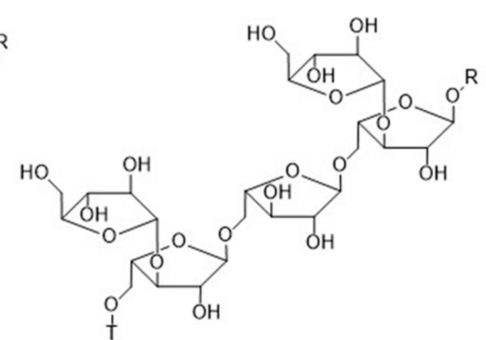

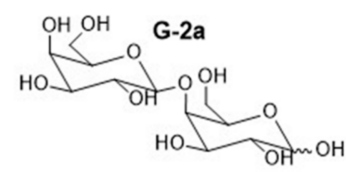


Figure A1. Arabinan and galactan oligosaccharides of IDF and SDF of enzymatically treated apple pomace (raw and extruded) after enzymatic cleavage by endo-arabinanase and endo-galactanase. IDF: insoluble dietary fiber, SDF: soluble dietary fiber, R: reducing end, T: terminal end.

\section{References}

1. Ribeiro, D.S.; Henrique, S.M.B.; Oliveira, L.S.; Macedo, G.A.; Fleuri, L.F. Enzymes in juice processing: A review. Int. J. Food Sci. Technol. 2010, 45, 635-641. [CrossRef]

2. Will, F.; Bauckhage, K.; Dietrich, H. Apple pomace liquefaction with pectinases and cellulases:analytical data of the corresponding juices. Eur. Food Res. Technol. 2000, 211, 291-297. [CrossRef] 
3. Ceci, L.; Lozano, J. Determination of enzymatic activities of commercial pectinases for the clarification of apple juice. Food Chem. 1998, 61, 237-241. [CrossRef]

4. Schieber, A.; Hilt, P.; Streker, P.; Endreß, H.-U.; Rentschler, C.; Carle, R. A new process for the combined recovery of pectin and phenolic compounds from apple pomace. Innov. Food Sci. Emerg. Technol. 2003, 4, 99-107. [CrossRef]

5. Bhushan, S.; Kalia, K.; Sharma, M.; Singh, B.; Ahuja, P.S. Processing of Apple Pomace for Bioactive Molecules. Crit. Rev. Biotechnol. 2008, 28, 285-296. [CrossRef] [PubMed]

6. Elleuch, M.; Bedigian, D.; Roiseux, O.; Besbes, S.; Blecker, C.; Attia, H. Dietary fibre and fibre-rich by-products of food processing: Characterisation, technological functionality and commercial applications: A review. Food Chem. 2011, 124, 411-421. [CrossRef]

7. Sloan, E. Dietary fiber moves back into mainstream. Food Technol. 2001, 55, 18.

8. Figuerola, F.; Hurtado, M.L.; Estévez, A.M.; Chiffelle, I.; Asenjo, F. Fibre concentrates from apple pomace and citrus peel as potential fibre sources for food enrichment. Food Chem. 2005, 91, 395-401. [CrossRef]

9. Gorinstein, S.; Caspi, A.; Libman, I.; Katrich, E.; Lerner, H.T.; Trakhtenberg, S. Comparative contents of dietary fiber, total phenolics, and minerals in persimmons and apples. J. Agric. Food Chem. 2004, 52, 5215-5222. [CrossRef]

10. Rana, S.; Gupta, S.; Rana, A.; Bhushan, S. Functional properties, phenolic constituents and antioxidant potential of industrial apple pomace for utilization as active food ingredient. Food Sci. Hum. Wellness 2015, 4, 180-187. [CrossRef]

11. Schmid, V.; Karbstein, H.P.; Emin, M.A. The Influence of Extrusion Processing on the Gelation Properties of Apple Pomace Dispersions: Involved Cell Wall Components and Their Gelation Kinetics. Foods 2020, 9, 1536. [CrossRef]

12. Zlatanović, S.; Kalušević, A.; Micić, D.; Laličić-Petronijević, J.; Tomić, N.; Ostojić, S.; Gorjanović, S. Functionality and Storability of Cookies Fortified at the Industrial Scale with up to 75\% of Apple Pomace Flour Produced by Dehydration. Foods $2019,8,561$. [CrossRef]

13. Cheftel, J.C. Nutritional effects of extrusion-cooking. Food Chem. 1986, 20, 263-283. [CrossRef]

14. Guy, R.C.E. Extrusion Cooking. Technologies and Applications; CRC Press: Boca Raton, FL, USA; Woodhead: Cambridge, UK, 2001; ISBN 0-8493-1207-8.

15. Hwang, J.-K.; Choi, J.-S.; Kim, C.-J.; Kim, C.-T. Solubilization of apple pomace by extrusion. J. Food Process. Preserv. 1998, 22, 477-491. [CrossRef]

16. Liu, G.; Ying, D.; Guo, B.; Cheng, L.J.; May, B.; Bird, T.; Sanguansri, L.; Cao, Y.; Augustin, M. Extrusion of apple pomace increases antioxidant activity upon in vitro digestion. Food Funct. 2019, 10, 951-963. [CrossRef] [PubMed]

17. Hwang, J.-K.; Kim, C.-J.; Kim, C.-T. Extrusion of apple pomace facilitates pectin extraction. J. Food Sci. 1998, 63, 1-4. [CrossRef]

18. Schmid, V.; Trabert, A.; Schäfer, J.; Bunzel, M.; Karbstein, H.P.; Emin, M.A. Modification of Apple Pomace by Extrusion Processing: Studies on the Composition, Polymer Structures, and Functional Properties. Foods 2020, 9, 1385. [CrossRef]

19. Wefers, D.; Gmeiner, B.M.; Tyl, C.E.; Bunzel, M. Characterization of diferuloylated pectic polysaccharides from quinoa (Chenopodium quinoa WILLD.). Phytochemistry 2015, 116, 320-328. [CrossRef] [PubMed]

20. Prosky, L.; Asp, N.-G.; Furda, I.; Devries, J.W.; Schweizer, T.F.; Harland, B.F. Determination of Total Dietary Fiber in Foods and Food Products: Collaborative Study. J. Assoc. Off. Anal. Chem. 1985, 68, 677-679. [CrossRef]

21. McCleary, B.V.; DeVries, J.W.; Rader, J.I.; Cohen, G.; Prosky, L.; Mugford, D.C.; Champ, M.; Okuma, K. Determination of total dietary fiber (CODEX definition) by enzymatic-gravimetric method and liquid chromatography: Collaborative study. J. AOAC Int. 2010, 1, 221-233. [CrossRef]

22. Urbat, F.; Müller, P.; Hildebrand, A.; Wefers, D.; Bunzel, M. Comparison and Optimization of Different Protein Nitrogen Quantitation and Residual Protein Characterization Methods in Dietary Fiber Preparations. Front. Nutr. 2019, 6, 127. [CrossRef] [PubMed]

23. Bunzel, M.; Ralph, J.; Marita, J.M.; Hatfield, R.D.; Steinhart, H. Diferulates as structural components in soluble and insoluble cereal dietary fibre. J. Sci. Food Agric. 2001, 81, 653-660. [CrossRef]

24. Gniechwitz, D.; Reichardt, N.; Blaut, M.; Steinhart, H.; Bunzel, M. Dietary Fiber from Coffee Beverage: Degradation by Human Fecal Microbiota. J. Agric. Food Chem. 2007, 55, 6989-6996. [CrossRef]

25. Sweet, D.P.; Shapiro, R.H.; Albersheim, P. Quantitative analysis by various glc response-factor theories for partially methylated and partially ethylated alditol acetates. Carbohydr. Res. 1975, 40, 217-225. [CrossRef]

26. Wefers, D.; Bunzel, M. Arabinan and Galactan Oligosaccharide Profiling by High-Performance Anion-Exchange Chromatography with Pulsed Amperometric Detection (HPAEC-PAD). J. Agric. Food Chem. 2016, 64, 4656-4664. [CrossRef]

27. Blumenkrantz, N.; Asboe-Hansen, G. New Method for Quantitative Determination of Uranic Acids. Anal. Biochem. 1973, 54, 484-489. [CrossRef]

28. Anderson, R.A. Water absorption and solubility and amylograph characteristics of roll-cooked small grain products. Cereal Chem. J. 1982, 59, 265.

29. Gogoi, B.K.; Choudhury, G.S.; Oswalt, A.J. Effects of location and spacing of reverse screw and kneading element combination during twin-screw extrusion of starchy and proteinaceous blends. Food Res. Int. 1996, 29, 505-512. [CrossRef]

30. Emin, M.; Wittek, P.; Schwegler, Y. Numerical analysis of thermal and mechanical stress profile during the extrusion processing of plasticized starch by non-isothermal flow simulation. J. Food Eng. 2021, 294, 110407. [CrossRef]

31. Sudha, M.; Baskaran, V.; Leelavathi, K. Apple pomace as a source of dietary fiber and polyphenols and its effect on the rheological characteristics and cake making. Food Chem. 2007, 104, 686-692. [CrossRef] 
32. Wefers, D.; Flörchinger, R.; Bunzel, M. Detailed Structural Characterization of Arabinans and Galactans of 14 Apple Cultivars Before and After Cold Storage. Front. Plant Sci. 2018, 9, 1451. [CrossRef] [PubMed]

33. Schmid, V.; Steck, J.; Mayer-Miebach, E.; Behsnilian, D.; Briviba, K.; Bunzel, M.; Karbstein, H.P.; Emin, M.A. Impact of defined thermomechanical treatment on the structure and content of dietary fiber and the stability and bioaccessibility of polyphenols of chokeberry (Aronia melanocarpa) pomace. Food Res. Int. 2020, 134, 109232. [CrossRef]

34. Emin, M.; Schuchmann, H. Analysis of the dispersive mixing efficiency in a twin-screw extrusion processing of starch based matrix. J. Food Eng. 2013, 115, 132-143. [CrossRef]

35. Thibault, J.-F. Effect of extrusion-cooking on pectin-rich material. In Pectines and Pectinases: Proceedings of an International Symposium, Wageningen, The Netherlands, 3-7 December 1995; Visser, J., Voragen, A.G.J., Eds.; Elsevier: Amsterdam, The Netherlands; New York, NY, USA, 1996; pp. 425-437. ISBN 9780444823304.

36. Ralet, M.-C.; Axelos, M.A.; Thibault, J.-F. Gelation properties of extruded lemon cell walls and their water-soluble pectins. Carbohydr. Res. 1994, 260, 271-282. [CrossRef] 